\title{
Biopolymers as Green Binders for Soil Improvement in Geotechnical Applications: A Review
}

\author{
Hadi Fatehi ${ }^{1,2, *(\mathbb{D})}$, Dominic E. L. Ong ${ }^{1,2}{ }^{\mathbb{C}}$, Jimmy Yu ${ }^{1} \mathbb{C}$ and Ilhan Chang ${ }^{3}(\mathbb{D}$ \\ 1 School of Engineering and Built Environment, Griffith University, Nathan, QLD 4111, Australia; \\ d.ong@griffith.edu.au (D.E.L.O.); jimmy.yu@griffith.edu.au (J.Y.) \\ 2 Cities Research Institute, Griffith University, Nathan, QLD 4111, Australia \\ 3 Department of Civil System Engineering, Ajou University, Suwon-si 16499, Korea; ilhanchang@ajou.ac.kr \\ * Correspondence: hadi.fatehigelab@griffithuni.edu.au
}

Citation: Fatehi, H.; Ong, D.E.L.; Yu, J.; Chang, I. Biopolymers as Green Binders for Soil Improvement in Geotechnical Applications: A Review. Geosciences 2021, 11, 291. https:// doi.org/10.3390/geosciences11070291

Academic Editors: Mohamed Shahin and Jesus Martinez-Frias

Received: 4 June 2021

Accepted: 13 July 2021

Published: 15 July 2021

Publisher's Note: MDPI stays neutral with regard to jurisdictional claims in published maps and institutional affiliations.

Copyright: (C) 2021 by the authors Licensee MDPI, Basel, Switzerland. This article is an open access article distributed under the terms and conditions of the Creative Commons Attribution (CC BY) license (https:// creativecommons.org/licenses/by/ $4.0 /)$.

\begin{abstract}
Soil improvement using biopolymers has attracted considerable attention in recent years, with the aim to reduce the harmful environmental effects of traditional materials, such as cement. This paper aims to provide a review on the environmental assessment of using biopolymers as binders in soil improvement, biopolymer-treated soil characteristics, as well as the most important factors affecting the behavior of the treated soil. In more detail, environmental benefits and concerns about the use of biopolymers in soil improvement as well as biopolymer-soil interaction are discussed. Various geotechnical properties are evaluated and compared, including the unconfined compressive strength, shear strength, erosion resistance, physical properties, and durability of biopolymer-treated soils. The influential factors and soil and environmental conditions affecting various geotechnical characteristics of biopolymer-treated soils are also discussed. These factors include biopolymer concentration in the biopolymer-soil mixture, moisture condition, temperature, and dehydration time. Potential opportunities for biopolymers in geotechnical engineering and the challenges are also presented.
\end{abstract}

Keywords: biopolymer-treated soils; soil improvement; geotechnical properties; biopolymer soil interaction

\section{Introduction}

Ground improvement is the deliberate enhancement of geotechnical properties of marginal soils to obtain the desired and optimal performance. When faced with a challenge, a geotechnical engineer would endeavor to develop the most effective and economical approach of soil treatment considering the underlying soil types, treatment depth, locations required to be treated, desired level of improvement, availability of skilled personnel and materials, environmental friendliness of the method and project costs. These design factors are the most effective in determining the appropriate treatment method [1]. Chemical modification is defined as the addition of additives to soils to alter the soil properties to be acceptable as defined in design criteria. Nowadays, numerous materials are being used for soil treatment. Lime and cement are considered among the most popular options. Often, additives such as sodium sulphate and fly ash are added to cement to enhance stabilization. Bitumen, chemical compounds, and geotextiles are the other materials which have been used for soil stabilization through various methods such as mixing materials and chemical grouting [2-8].

Global warming and climate change are considered among the most concerning phenomena in recent decades. In the case of materials used in civil applications, traditional and calcium-based materials, such as cement and lime, and synthetic products, have led to greenhouse gases (GHG) emissions, which are directly related to global warming. Therefore, alternative and less polluting materials should be encouraged [9-12]. 
Although cement production has remained unchanged during the past six years, it is still considered one of the main sources of $\mathrm{CO}_{2}$ emissions, contributing approximately $8 \%$ of the global $\mathrm{CO}_{2}$ emissions [13]. From 2010 to 2018, the global amount of cement production increased from 3310 to 4100 million tons (23.8\% increase) [14]. To reduce cement usage, researchers have attempted to replace traditional environmentally harmful materials with sustainable techniques and methods, such as bio-enzymes, $\mathrm{CO}_{2}$ absorption, microbial-induced calcite precipitation (MICP) method with viable but low-cost medium, and biopolymers [15-20].

In recent years, different solutions have been developed for environmentally friendly soil improvement, some of which are based on microbial activities and biomaterials. MICP is a multi-disciplinary technique combining the fields of microbiology, biology, and geotechnical engineering [21]. MICP is the process of using bacteria to precipitate calcite $\left(\mathrm{CaCO}_{3}\right)$ in the soil matrix, which leads to soil strengthening [22-24]. The formed $\mathrm{CaCO}_{3}$ network links the soil grains firmly and while the changes in subsurface conditions are not permanent, the longevity of treated soil mass can be adopted based on project needs and requirements [25]. Another advantage of MICP is to reduce the improved soil permeability to mitigate liquefaction by either bioclogging process or allowing the excess pore water pressure to be dissipated [26]. On the other hand, MICP disadvantages are the requirement of highly specialized sets of environmental and growth conditions, applicability to mostly in coarse-grained soil [27-29], producing ammonia as a by-product [30], and difficulty in gaining a uniform distribution of calcite [25].

In addition, enzymes can also be used to obtain calcite through the same biochemical reactions as in MICP. This improvement method is called enzyme-induced calcium carbonate precipitation (EICP) [31]. Another biological method used is stimulating microbes to generate biopolymer (microbial biopolymer accumulation) within the soil matrix, to improve the soil against erosion and permeability reduction [32-34]. Biofilm formation has a beneficial effect on soil stability and the reduction of soil hydraulic conductivity [26,35-39]. Biogas generation, such as nitrogen, is also a biological method by which the liquefaction potential of sand is decreased. The production of insoluble gases in soil pores leads to a reduction in the degree of soil saturation, to mitigate the liquefaction hazard $[40,41]$.

Polymers are macromolecular materials that are composed of repeating subunits (monomers). There are two types of polymer: synthetic and natural. Synthetic polymers are those produced from petroleum products. Biopolymers are natural polymers that are produced naturally in the environment by plants and living organisms [42]. They have an extensive record in different applications in the construction industry [43]. The majority of biopolymers have been employed as adhesive or water retention agents. Lignin and its derivatives are effective as an additive in concrete and oil well drilling. Cellulose and starch derivatives performed well in various applied fields such as tile adhesives, oil well construction, ceramics, and cement and lime plasters [44-46]. Biopolymers have been used in drilling fluids because they require low viscosity during pumping and high viscosity after circulation has stopped; specific features conferred by xanthan to the solution.[47-50].

In geotechnical engineering, biopolymer binders potentially have a notable effect on enhancing various aspects of marginal soil behaviors. The beneficial effects and advantages of biopolymers have been reviewed in recent review papers from different points of view. However, there is still a gap in understanding of the behavior of biopolymertreated soil under diverse loadings and environmental conditions. An environmental assessment is undertaken in this study which presents the factors that must be considered when using biopolymers during their life cycle. Also, it is necessary to understand how different parameters could influence the biopolymer interaction processes with soil particles before, during, and after mixing, with particular reference to curing conditions, as well as environmental factors. This paper endeavors to update and comprehensively review the studies on biopolymer-treated soil from the perspective of geotechnical engineering, including the evaluation of unconfined compressive strength, shear strength, erosion resistance, Atterberg limits, compaction characteristics, and pavement stabilization. The 
various parameters influencing the improved soil geotechnical performance were evaluated under the optimal conditions for each type of biopolymer. Moreover, the interaction processes of biopolymers with different soil types were also discussed.

\section{Biopolymers in Geotechnical Applications}

Biopolymers can be classified based on different terms including biodegradability (biodegradable and non-biodegradable) and the source of raw materials. Three groups can be considered when classifying biopolymers based on their source of origin: plantbased biopolymers, animal-based biopolymers, and biopolymers produced by microorganisms [51]. Figure 1 presents a list of biopolymers, which are mostly utilized for soil improvement purposes, based on the source of production.
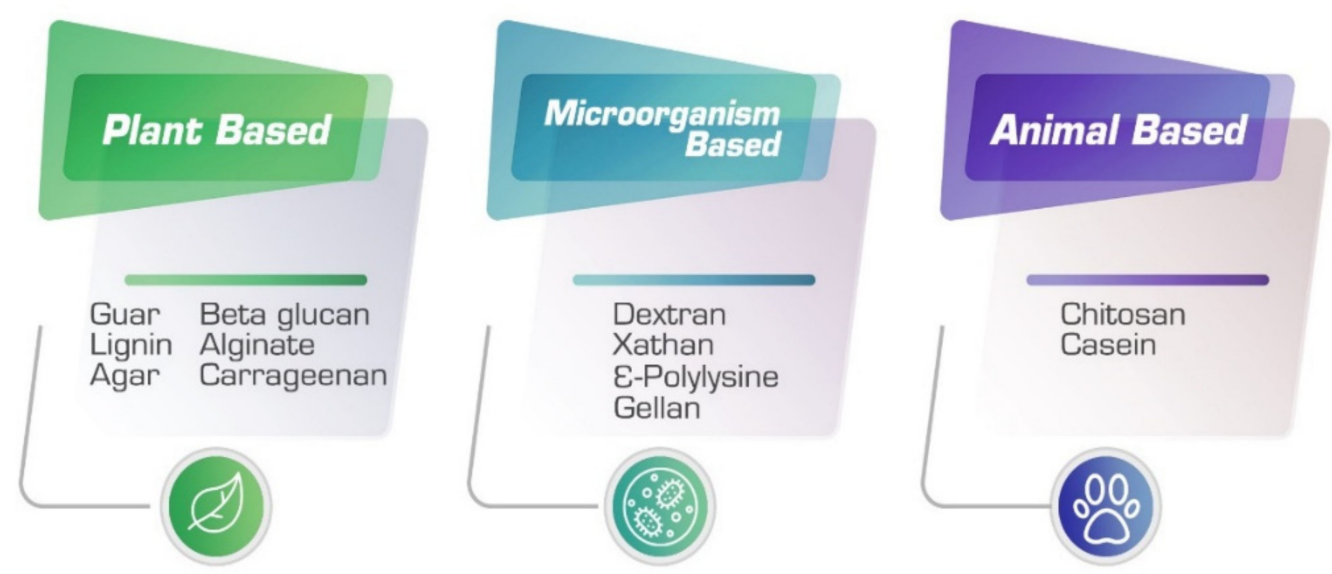

Figure 1. Common biopolymers used for soil improvement based on their source of production.

\subsection{Plant-Based Biopolymers}

Plant-based biopolymers are produced from plants and agricultural scraps. Biopolymers in geotechnics mainly include plant-based products which are mostly polysaccharides. Guar, lignin, agar, beta-glucan, alginate, and carrageenan fall into this category. Guar gum (guaran) is a polysaccharide composed of two sugars galactose and mannose, extracted from the guar plant. Among water-soluble polysaccharides, guar gum is the one with the highest molecular weight [52]. Guar gum is a naturally charged polysaccharide that can be found in both cationic and anionic states. The world production for the guar gum family is more than 1 million tons each year so that it is commercially available at a reasonable cost. The presence of large hydroxyl groups in guar gum produces a network of hydrogels among soil particles and hydrogen ions through hydrogen bonds [53,54].

Lignin makes an influential contribution to the formation of cell walls, especially in trees and barks. After cellulose, lignin is the most abundant biopolymer existing throughout the world. It is relatively hydrophobic and a recalcitrant biopolymer (resistant against acidand base-catalyzed hydrolysis) [55]. Due to it being a natural adhesive and its phenolic nature, lignin has been considered a good replacement for wood adhesives [56]. Being cheaper, environment-friendly, and non-toxic has made lignin an appropriate alternative for traditional stabilizers [57]. A stable soil structure is formed when lignin links soil particles together and leads to the reduction of big pores in the soil [58].

Agar gum is a thermogelatin polysaccharide extracted from seaweed (i.e., marine red algae) [59]. This biopolymer tends to dissolve in water at temperatures around $85^{\circ} \mathrm{C}$ and to form a gel when cooled to $32-43{ }^{\circ} \mathrm{C}$ [60]. The conventional agar production process consists of key stages of pre-treatment, extraction, filtration, concentration, and dehydration [61]. The properties of agar gum are greatly dependent on the seaweed utilized for agar production [61]. Because of having comparatively long molecular structure and low ionic inclination, agar gums act to coat and coagulate soil grains, and direct interactions with soil particles would be difficult for agar gum due to its neutral charged nature [62]. 
Beta-glucan biopolymer is a natural polymer found in the cell walls of yeast and cellulose in plants. It is a biopolymer of D-glucose monomers linked by glycosidic bonds [63]. The potential of beta-glucan biopolymer to form hydrogen bonds is relatively high due to the hydroxyl and carboxyl (COO-) on the edges, which cause surface polarization, creating a greater capacity for water adsorption by beta-glucan, and resulting in pore filling and volumetric expansion of soil.

Sodium alginate is an anionic polysaccharide with the chemical formula $\mathrm{C}_{5} \mathrm{H}_{7} \mathrm{O}_{4} \mathrm{COONa}$, and it is a salt produced from alginic acid [64]. It is mostly produced from the cell walls of marine brown algae [64]. Alginate is a water-soluble biopolymer and forms a viscous gum by linking with water molecules [65]. Biocompatibility, low toxicity, and relatively low cost make alginate a good choice for soil improvement applications. Also, $\mathrm{pH}$ can significantly affect the viscosity of alginate solution. A pH reduction results in a decrease in viscosity [64]. Moreover, highly charged molecules, hydrophobic and polar moieties, as well as the side chain carboxylates provide sodium alginate with a distinctive potential additive in soils [66]. Carrageenan is known as a linear polysaccharide produced from red edible seaweeds. Carrageenan is an anionic biopolymer and is soluble in water. In low $\mathrm{pH}$ with high temperatures, the stability of carrageenan is expected to decrease [67].

\subsection{Microorganism-Based Biopolymers}

Biopolymers such as xanthan gum, gellan gum, and dextran, are the products of bacterial fermentation processes, which are considered microorganism-based biopolymers. Xanthan gum is a microorganism-based anionic polysaccharide, produced through glucose/sucrose fermentation by the Xanthomonas campestris bacterium. The most well-known characteristics of xanthan gum are pseudo-plasticity [68] and high shear stability [69] even at relatively low concentrations. Moreover, it has several desirable properties, including $\mathrm{pH}$ stability, storage stability, and ionic salt compatibility xanthan has found a wide range of applications in cosmetics, oil, paper, paint, pharmaceuticals, and food and textile industries as a gelling, thickening, or suspending agent, and as a flocculent or for viscosity control [70]. Gellan gum is a thermogelatin anionic polysaccharide with a high molecular weight that is produced through bacterial fermentation of Sphingomonas elodea [71]. In commercial applications, thermal behavior of gellan gum is used as deacylated polymer which is soluble in water at temperatures higher than $90^{\circ} \mathrm{C}$. It then forms a gel when the temperature is reduced [62]. This biopolymer has a remarkable ability to form high-quality gels, and has also been found to be stable at high temperatures and low $\mathrm{pH}$ conditions [72]; these features make this biopolymer a suitable additive for soil improvement.

Polylysine is a lysine homopolymer that includes functional carboxyl and $\varepsilon$-amino groups. It is a cationic polymer [73]. This biopolymer is produced by bacterial fermentation typically in the strains in the genus Streptomyces and has both hydrophobic and hydrophilic properties [74]. The positive charges of $\varepsilon$-polylysine are capable of interacting with negatively charged surfaces such as fine clay [73]. Dextran is a natural polymer and a complex branched glucan that is synthetized from sucrose by certain lactic-acid bacteria. Dextran is insoluble in water and $\mathrm{pH}$ does not affect its solubility. Dextran solutions behave like Newtonian flow characteristics [75]. In geotechnical purposes, as dextran is produced through a microbial process, a bacterium named Leuconostoc mesenteroides was cultured and stimulated in fine sand to generate dextran to reduce the surface erosion rate [34].

\subsection{Animal-Derived Biopolymers}

Animal-derived biopolymers are the polymers produced from animal sources. Chitin and chitosan are produced from the waste crustacean shells such as shells of shrimps, and protein-based biopolymers are produced from milk and dairy products. Chitosan is a water-soluble biopolymer that tends to bind to negatively charged surfaces [76]. Chitosan is a linear polysaccharide of D-glucosamie and N-acetyl-D-glucosamine, which is usually extracted from crustacean shells of the food processing industry [77]. Chitosan is an animal-based biopolymer with cationic nature, and because of the positive charges of 
amino groups, it becomes a cationic polyelectrolyte after being dissolved in acetic acid [78]. This cationic feature allows it to interact with chitosan and the negatively charged double layer of clay $[79,80]$. Casein is a type of protein biopolymer which is negatively charged at a $\mathrm{pH}$ of 6.6 with an isoelectric point is around 4.6 [81]. A high-quality casein for soil treatment applications is obtained when extracted from skim milk with the lowest fat amount [82]. Compared with other biopolymers, protein-based biopolymers have a less hydrophilic tendency to water absorption [83]. As the polymeric chains of casein reach into the soil particles, the soil and biopolymer are joined together through electrostatic interaction among protein functional groups [82]. Table 1 presents the most important details of the common biopolymers in soil strengthening.

Table 1. Characteristics of common biopolymers utilized for soil treatment and their potential environmental impacts.

\begin{tabular}{|c|c|c|c|c|}
\hline Biopolymer & Source & Charge Type & Water Solubility & $\begin{array}{l}\text { Potential Environmental } \\
\text { Impact }\end{array}$ \\
\hline Xanthan Gum & $\begin{array}{c}\text { glucose or sucrose } \\
\text { fermentation by the } \\
\text { Xanthomonas campestris } \\
\text { bacterium }\end{array}$ & anionic & soluble & $\begin{array}{l}0.1 \mathrm{~kg} \mathrm{CO}_{2 \mathrm{e}} \text { for production of } \\
1 \mathrm{~kg} \text { biopolymer, no land use }\end{array}$ \\
\hline Gellan gum & $\begin{array}{l}\text { bacterial fermentation of } \\
\text { Sphingomonas elodea }\end{array}$ & anionic & $\begin{array}{l}\text { soluble at temperatures } \\
\text { higher that } 90{ }^{\circ} \mathrm{C}\end{array}$ & $\begin{array}{c}\text { Low } \mathrm{CO}_{2} \text { record, no land use, } \\
\text { and no pesticides }\end{array}$ \\
\hline Beta glucan & $\begin{array}{l}\text { in cell walls of yeast and } \\
\text { cellulose in plants }\end{array}$ & cationic & soluble & $\begin{array}{l}\text { Low carbon footprint, } \\
\text { relatively high water footprint }\end{array}$ \\
\hline Agar gum & marine algae & neutral & soluble around $85^{\circ} \mathrm{C}$ & $\begin{array}{l}\text { Negligible carbon footprint } \\
\text { and very low water footprint }\end{array}$ \\
\hline $\begin{array}{l}\text { Lignin and its } \\
\text { derivatives }\end{array}$ & $\begin{array}{l}\text { cell walls of trees and } \\
\text { barks(produced from the } \\
\text { waste by-product of paper } \\
\text { manufacturing industry) }\end{array}$ & mostly anionic & insoluble & $\begin{array}{c}\text { Second largest biopolymer in } \\
\text { nature, relatively high land } \\
\text { use, low carbon footprint }\end{array}$ \\
\hline Sodium alginate & brown algae & anionic & soluble & $\begin{array}{l}\text { Low energy needed, low } \\
\text { acidification by using } \\
\text { hydrochloric acid }\end{array}$ \\
\hline Chitosan & waste crustacean shells & cationic & soluble & $\begin{array}{l}\text { Low greenhouse emissions if it } \\
\text { is used as fertilizer; Producible } \\
\text { from waste animal products }\end{array}$ \\
\hline Carrageenan & red edible seaweeds & anionic & soluble & - \\
\hline Casein & (waste) dairy products & anionic & insoluble & $\begin{array}{l}\text { High water and } \\
\text { carbon footprint; } \\
\text { Producible from waste } \\
\text { dairy product }\end{array}$ \\
\hline Guar gum & guar plant & cationic/anionic & soluble & Low carbon footprint \\
\hline Polylysine & bacterial fermentation & cationic & soluble & - \\
\hline Dextran & $\begin{array}{l}\text { synthetized from sucrose by } \\
\text { certain lactic-acid bacteria }\end{array}$ & anionic/cationic & insoluble & $\begin{array}{c}\text { Low } \mathrm{CO}_{2} \text { record, no land use, } \\
\text { and no pesticides }\end{array}$ \\
\hline
\end{tabular}

\section{Assessment of Environmental Impacts of Biopolymers in Geotechnical Engineering}

More recently, many industrial policies have been developed towards sustainability, mainly to mitigate the harmful environmental impacts. In this way, the EU commission is set to cut GHG emissions by more than $85 \%$ by 2050 compared to the level of 1990 [84]. With rising concerns about planet environmental consequences, soil improvement methods are turning to less harmful methods and materials [85]. Some techniques, such as lifecycle assessment (LCA), have been developed to systematically analyze the environmental performance of processes or materials. LCA investigates the environmental costs and 
impacts for the entire process from the extraction of the raw materials to final disposal. As an example of a geotechnical work, the life cycle for a road construction project can be summarized in five sections [86,87]:

1. Manufacturing processes for all materials used in the project, including extraction, transportation of raw material from the source to the factory, processing to the final product, and material transportation to the construction site.

2. Construction stage, which is a phase that consists of all the execution processes required for a road to be taken. This includes all the components causing the production of greenhouse gas emissions, even the fuel consumed by the vehicles experiencing delays caused by the project.

3. Use phase, in which most factors are related to the energy and air pollution resulting from road vehicles. Leaching and runoff leading to water pollution is an important parameter to be considered in the use phase.

4. Maintenance and rehabilitation (M\&R), a very important section to keep the functionality of a road through its functional life span. Road works to repair possible road damage as well as the traffic occurring due to delays are undertaken in this part. More technically, this includes production and transportation of new materials to the site, and destruction and discarding rubbish materials.

5. End-of-life stage includes the way that disposal materials are to be used, whether recycling or disposing of the materials into the environment. The activities are about demolition and transportation, as well as leaching if the materials are disposed of at the end.

Various factors must be considered when an environmental assessment work is being studied, including acidification potential, aquatic toxicity, human toxicity potential, eutrophication potential (considering the pollution of aquatic ecosystems), global warming potential, non-renewable resource depletion, ozone depletion potential, terrestrial ecotoxicity, and photochemical oxidants creation potential [84]. Among these, global warming, acidification, eutrophication, and human toxicity are the most important ones for geotechnical works [88]. Therefore, the environmental assessment for geotechnical applications is necessary.

Chemical soil treatment is recommended to reduce the transportation cost of virgin materials to the site and disposals in landfills [87]. Lime stabilization decreased the energy consumption by $30 \%$ and the $\mathrm{CO}_{2}$ production by $27 \%$ compared with the employment of virgin materials.

Although chemical soil treatment is more preferable to virgin materials, the lime and cement industries contribute to the production of a considerable amount of GHG emissions. The cement industry generates about 2.8 billion tons of $\mathrm{CO}_{2}$, equal to $8 \%$ of total $\mathrm{CO}_{2}$ amount. More than half of these emissions are produced through the chemical process of calcination for making the clinkers [89], which cannot be mitigated by increasing energy efficiency or using renewable fuel resources. Hydrated lime manufacturing comprises extracting limestone and transporting it to the factory, calcination, and quicklime hydration; this is an energy-intensive procedure (vertical kiln), and this energy is mostly provided from non-renewable resources [90].

For soil improvement using lime, more than $75 \%$ of all environmental impacts, including global warming, photochemical oxidation, and embodied energy, are contributed by lime production [90]. Also, treated soil with low density lime binder showed twice larger energy consumption than the treated soil with high-density lime binder, when the goal was reaching a certain strength $[90,91]$; it can be concluded that chemical soil treatment is preferred to be conducted using binders with high density and low content, which is an advantage for biopolymers as much less content is needed compared with traditional binders.

Recently, the goal of moving towards sustainability has been followed in polymeric materials so that biopolymers have attracted more attention [92]. The biopolymer concept is a polymer that is totally or partly generated from a bio-based source and is somehow 
biodegradable. The application of biopolymers in various industries helps them to progress in the way of sustainability, however, the presence of some fundamental issues has limited the development of biopolymers in certain industries [93]. Advancement in the biopolymer industry can reduce not only the environmental impacts but also the costs, and strong market potential for biopolymers is estimated in the near future. On the other hand, some synthetic polymers give a better performance in terms of mechanical and thermal resistance [84].

A comprehensive study conducted by the Institute for Energy and Environmental Research (IFEU) concluded that biopolymers perform better than conventional polymers in terms of climate impact, particularly in $\mathrm{CO}_{2}$ emissions and fossil fuel consumption [94]. Although a bright future can be seen for biopolymers, the potential environmental impacts of the biopolymers cannot be ignored. Few studies have been undertaken so far on the economic and environmental impacts of the biopolymers because they are in an early development stage and have a relatively small market share of the polymers. Most LCA studies on biopolymers are incomplete or are based on a laboratory-scale dataset.

The way biopolymers are degraded when they are used in large volume raises concerns about contamination by entering streams, rivers, and the ocean, as some biopolymers degrade slowly which makes them applicable for use in long-term geotechnical applications [95]. Another concern is the land use for biopolymer production that might occupy the land required to grow crops for food industries. Expanding biopolymer production requires fertilizers for the plants from which biopolymers are extracted, and may lead to a higher level of water eutrophication and soil acidification than to the production of chemical polymers. Also, through the production process and transportation of biopolymers, energy and water must be provided that causes GHG emissions, however, the emission is around $85 \%$ less than conventional polymers and much less than traditional adhesives, such as cement and lime.

Environmental impacts for the biopolymers used for soil improvement vary. The amount of GHG emissions generated through biopolymer production cannot be measured accurately, because it is dependent on many factors based on the local conditions and available resources, such as the energy supply pathways, fuel source, and production method. Lignin combustion, which is used as biofuel, decreases GHG emissions by more than $80 \%$ relative to gasoline [96]. There are a number of lignin production methods, and climate change impact is variable for each of them, resulting from the highest impact for the cheapest lignin to the least impact for the most expensive lignin. The carbon footprint for xanthan gum is reported to be very low, at $0.1 \mathrm{~kg} \mathrm{CO}_{2 \mathrm{e}}$ for production of $1 \mathrm{~kg}$ biopolymer, with still unknown water footprint [97]. The carbon footprint comes to a negligible amount for agar biopolymer [98]. Guar is a low-emission crop that produces $\mathrm{CO}_{2}$ mostly through irrigation, fertilization, and harvesting and threshing process; $\mathrm{CO}_{2}$ comes from electricity for irrigation, from production and application for fertilization, and the fossil fuels for harvesting and threshing [99].

Beta-glucan is usually produced from oats, and is considered as a low carbon footprint. The carbon emission amount is variable based on the location of source and processing. The largest global warming contribution is from the production and the use of nitrogen fertilizer, as well as the energy used through field activities [100]. The water footprint for beta-glucan is relatively higher with more than 300 gallons needed to produce one kilogram of oats [101,102]. Sodium alginate has low environmental impact, among which electricity accounts for 39\% of this followed by the use of chemicals (hydrochloric acid), $26 \%$ on average [103].

One of the main concerns of chitosan environmental impacts is that it is the source of ammonia and greenhouse emissions for heat production and when it is used as fertilizer [104]; 2.7\% of global GHG emissions are attributed to dairy products, which do not contribute to $\mathrm{CO}_{2}$ production, significantly; they are dominated by methane $(\mathrm{CH} 4)$ and nitrous oxide (N2O). On average, $2.4 \mathrm{~kg}$ carbon dioxide equivalent is produced per $\mathrm{kg}$ of milk, which makes the dairy industry one of the main contributors to climate change. 
Land use and water consumption are the other impacts of dairy products $[105,106]$. Even though producing casein causes serious environmental concerns, casein utilized for soil improvement comes from waste dairy products that are usually dumped into the environment, so that casein cannot only be utilized in soil treatment, but also keeps the environment from being contaminated and brings the recyclability into the dairy products' life cycle [82,107]. Recently, significant advancement in biotechnology has provided the opportunity for biopolymer production, such as xanthan, dextran, and gellan gum, directly by microorganism fermentation of glucose or sucrose or genetically modified crops [108], under controlled conditions; this provides the opportunity to have biopolymers generating less $\mathrm{CO}_{2}$ and using less land, and there is no need for pesticides.

As mentioned, most of the environmental impacts in road works are related to the material production phase, and low content binders with high efficiency are recommended; so utilizing biopolymers to a large extent meets both conditions by lowering the GHG emissions in their production process and a comparatively low content is needed for soil treatment. For a simple soil improvement project of biopolymer-treated soil, the life cycle can be assumed as shown in Figure 2, showing the process for xanthan biopolymer as the most commonly used biopolymer. Three major parts are included: biopolymer production and transportation, soil extraction and transportation, and blends production.

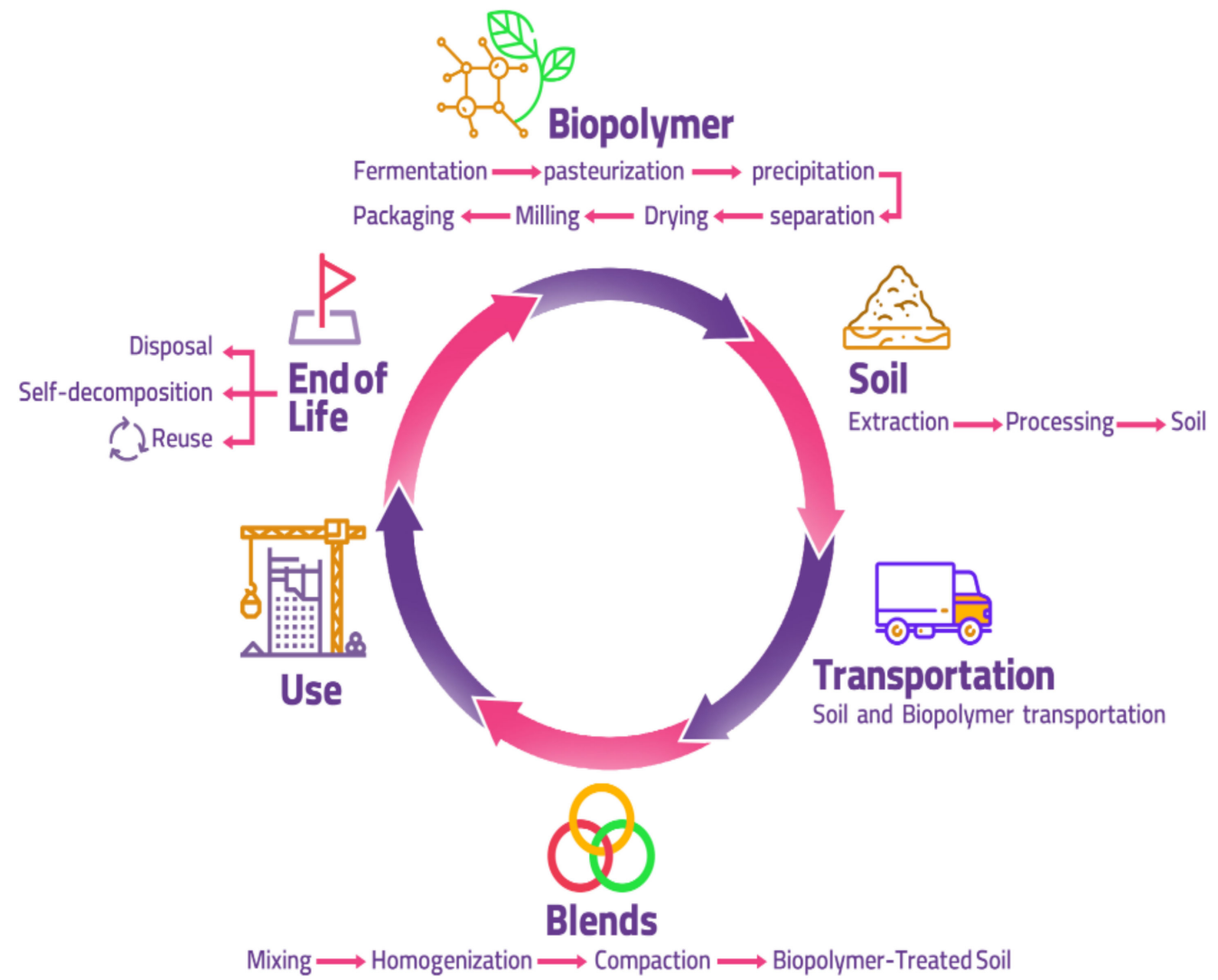

Figure 2. Life-cycle process of a xanthan treated soil.

\section{Biopolymer-Soil Interaction}

The way that a biopolymer interacts with different kinds of soils has always been considered as an important factor because microstructural study leads to a better understanding of the biopolymer-treated soil behavior. Based on the soil type, the adhesion mechanism of biopolymers is different from one soil to another. Figure 3 shows the schematic form of biopolymer-soil interaction. 


\section{(a)}
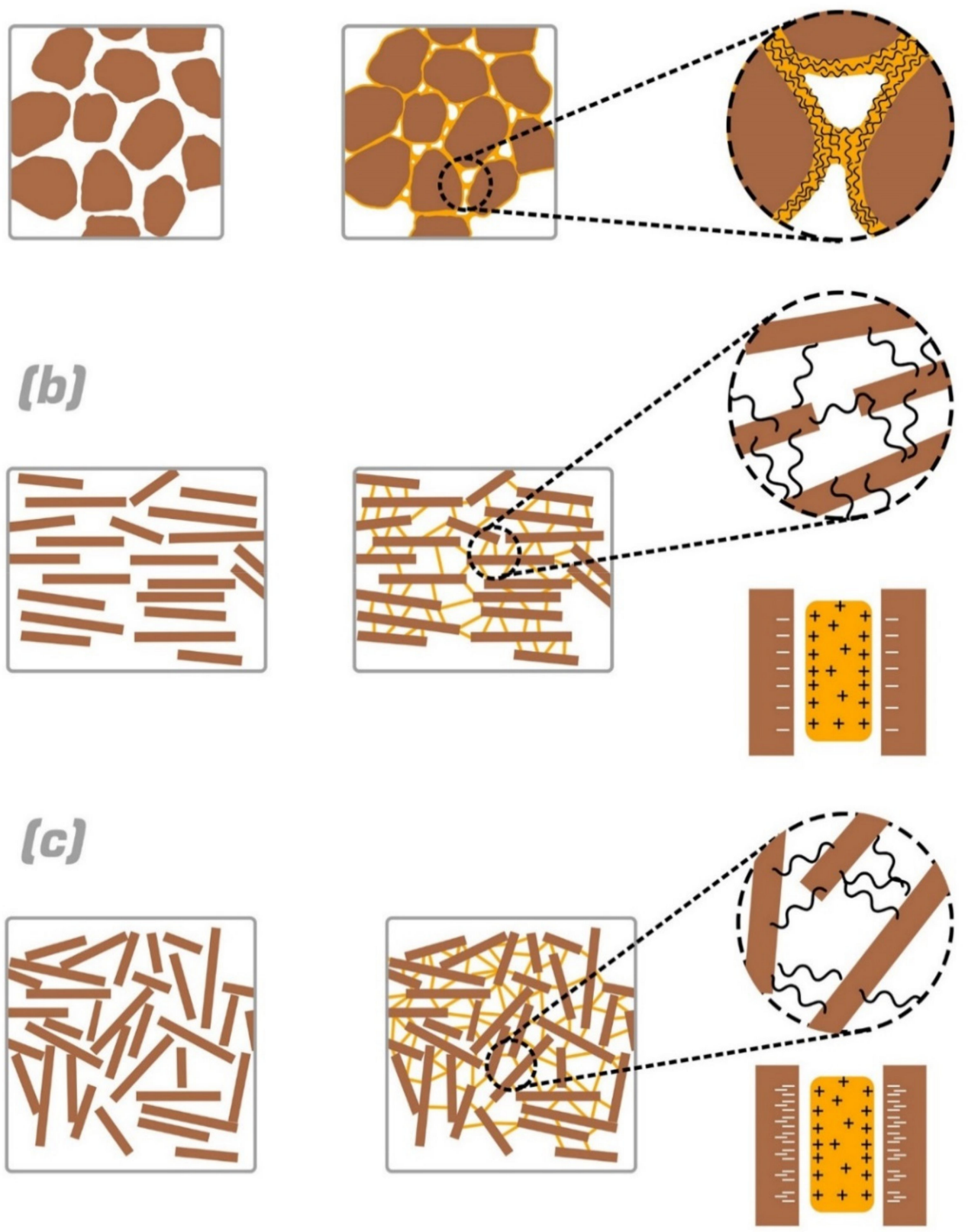

Figure 3. Biopolymer interaction with different kinds of soils (a) sand, (b) kaolinite clay, (c) montmorillonite.

\subsection{Biopolymer-Sand Interaction}

By adding biopolymer solution to sandy soils, the dissolved bound particles start to permeate into the pores and soak the sand surface. The hydrophilic feature of the sand surface, due to the presence of silica and silicate, as well as the water solubility of biopolymers, quicken the wetting process. When the biopolymer contacts the sand surface, it coats the soil particles and forms a strong film, thus creating the necessary bridges to start the bonding process. By allowing water evaporation over the curing period, the dehydration process of the biopolymer matrix promotes the bonding strength, drawing the particles closer to one another, thus compressing the pore spaces. Having shorter connection chains makes them stronger against external forces so that the geotechnical performance is enhanced during the drying procedure. More biopolymer (up to its optimal content) leads to the formation of higher bonds amongst sand particles and higher shear 
strength. Figure 3a shows the mechanism of biopolymer adhesion in typical biopolymertreated sand.

\subsection{Biopolymer-Clay Interaction}

The interaction mechanism of biopolymer with clayey soils is different from the coarsegrained soils because clay can be structurally transformed over time. In clay minerals, the composition changes within the structures due to substitution of ions. Replacing one structural cation by another of a similar size without changing the basic structure is called isomorphous substitution. This process determines the primary source of electrical charges (negative and positive) in clay minerals [109]. Kaolinite and montmorillonite are the most common clay minerals in the majority of soils. Kaolinite can carry both negative and positive charges, while montmorillonite carries negative charge in most cases [110]. Due to weathering of clay minerals in harsh climate conditions, hydrated oxides of iron (goethite) and aluminum (gibbsite) are generated, thus forming cations over clay sheets. In the case of gibbsite, hydroxyl ions bond with only two positive ions $\mathrm{Al}^{3+}$, so that positive ions remain available in clay structure.

Based on the clay minerals, the inter-layer bonding could have specific characteristics and a tendency to absorb water as well as ions. The layers in kaolinite clay are mostly connected through hydrogen bonds, thus kaolinite has a relatively stable structure with a lower tendency to absorb water and with lower swelling potential. The cation exchange capacity (CEC) of kaolinite is in the range of $0.03-0.1 \mathrm{meg} / 100 \mathrm{~g}$, which is lower than illite and montmorillonite. This feature makes kaolinite less tendentious to absorb biopolymer particles (see Figure 3b), although new cementitious compounds were produced after adding xanthan to kaolinite clay and subsequently with their pore spaces filled [111].

In montmorillonite, clay sheets are joined by van der Waals bonding, which is a comparatively weak chemical bond that allows water to easily enter between layers. Montmorillonite has a higher expansion potential when it is subjected to water, because of weak chemical bonding. Compared with kaolinite, as can be seen from Figure $3 c$, higher negative charges exist in montmorillonite with a CEC in the range around $0.8-1.5 \mathrm{meg} / 100 \mathrm{~g}$. Additionally, the specific surface area of montmorillonite is much larger than that of kaolinite. Consequently, montmorillonite is more likely to absorb a biopolymer solution thus reducing its swelling potential $[109,112]$. Illite is another silicate clay with a relatively fluctuated structure similar to montmorillonite, the difference is that cations are located among the surfaces causing the formation of ionic bonds. In terms of strength, ionic bonds are stronger than van der Waals bonds, such that illite has a lesser tendency to absorb water than montmorillonite.

In general, clay soils interact with biopolymer particles in a more complex way than the sand. biopolymer can directly interact with clay particles due to the presence of electrical charges. These chemical bonds could be formed through different electrostatic interactions, hydrogen bonding, ionic bonds, or van der Waals bonds. The factors that determine the mechanism of biopolymer-treated interaction include the electrical charges of the biopolymer, natural cations inside the clay, and the amount of charge in the clay sheet surfaces. Moreover, biopolymer coats the soil grains and connects detached particles by forming bridges along with direct chemical bonds. It has also been shown that the specific surface area is reduced when xanthan gum is added to the clay, due to filling the pores $[80,111,113-115]$. Comparing sandy and clayey soils, biopolymer-treated clay is expected to have a better efficiency because of the stronger interparticle connections between biopolymer and soil particles when compared with sand [113]. A summary of recent studies on biopolymer-treated soil is presented in Table 2. 
Table 2. A summary of recent studies on biopolymer-treated soils.

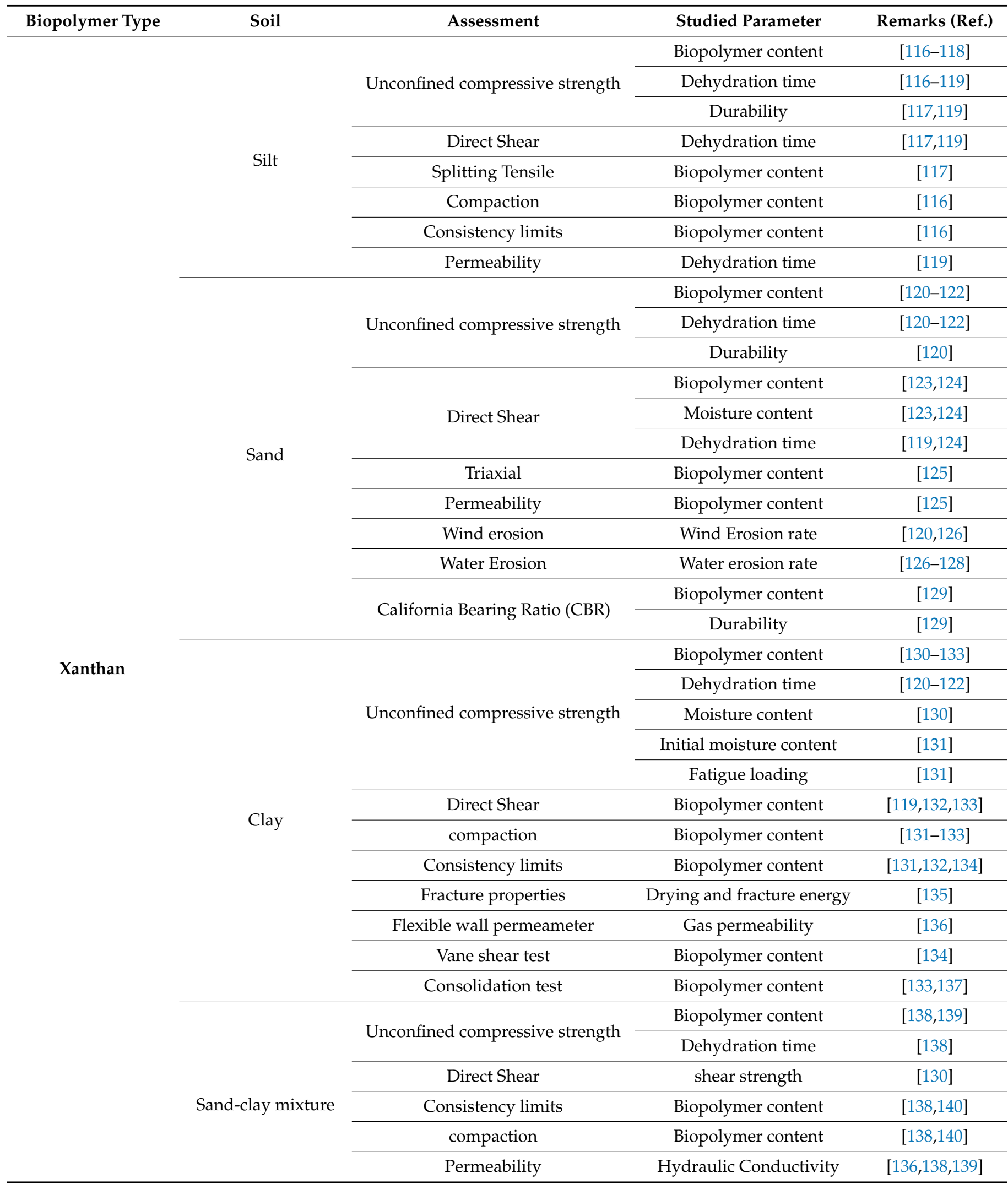


Table 2. Cont.

\begin{tabular}{|c|c|c|c|c|}
\hline Biopolymer Type & Soil & Assessment & Studied Parameter & Remarks (Ref.) \\
\hline & & Dispersivity tests & Dispersive properties & [140] \\
\hline & & Water Erosion & Erosion rate & {$[140,141]$} \\
\hline & & Consolidation test & Biopolymer content & [140] \\
\hline \multirow{21}{*}{ Guar } & \multirow{5}{*}{ Silt } & \multirow{3}{*}{ Unconfined compressive strength } & Biopolymer content & [117] \\
\hline & & & Dehydration time & [117] \\
\hline & & & Durability & [117] \\
\hline & & Direct Shear & Dehydration time & [117] \\
\hline & & Splitting Tensile & Biopolymer content & [117] \\
\hline & \multirow{5}{*}{ sand } & \multirow{3}{*}{ Unconfined compressive strength } & Biopolymer content & [120] \\
\hline & & & Dehydration time & [120] \\
\hline & & & Durability & [120] \\
\hline & & Triaxial & Biopolymer content & [125] \\
\hline & & Permeability & Biopolymer content & [125] \\
\hline & \multirow{6}{*}{ Clay } & \multirow{3}{*}{ Unconfined compressive strength } & Biopolymer content & {$[130,142]$} \\
\hline & & & Dehydration time & [130] \\
\hline & & & Moisture content & [130] \\
\hline & & Direct Shear & shear strength & [130] \\
\hline & & Permeability & Biopolymer content & [142] \\
\hline & & Compaction & Biopolymer content & [142] \\
\hline & \multirow{5}{*}{ Sand-clay mixture } & \multirow{2}{*}{ Unconfined compressive strength } & Biopolymer content & [143] \\
\hline & & & Durability & [143] \\
\hline & & Consistency limits & Biopolymer content & [143] \\
\hline & & Permeability & Hydraulic Conductivity & {$[136,143]$} \\
\hline & & Consolidation & Biopolymer content & [143] \\
\hline \multirow{6}{*}{ Sodium alginate } & \multirow{5}{*}{ Silt } & \multirow{4}{*}{ Unconfined compressive strength } & Biopolymer content & {$[117,144]$} \\
\hline & & & Dehydration time & [117] \\
\hline & & & Durability & [117] \\
\hline & & & Moisture effect & [144] \\
\hline & & Splitting Tensile & Biopolymer content & [117] \\
\hline & Sand & Wind erosion & Erosion rate & [145] \\
\hline \multirow{8}{*}{ Lignin } & \multirow{8}{*}{ Silt } & \multirow{2}{*}{ Unconfined compressive strength } & Biopolymer content & [146] \\
\hline & & & Cuing time & [146] \\
\hline & & Compaction & Biopolymer content & [147] \\
\hline & & \multirow{3}{*}{ Dynamic triaxial } & Biopolymer content & [147] \\
\hline & & & Curing time & [147] \\
\hline & & & $\begin{array}{l}\text { Dynamic shear modulus } \\
\text { and Damping ratio }\end{array}$ & [147] \\
\hline & & Consistency limits & Biopolymer content & [146] \\
\hline & & Direct shear & Biopolymer content & [146] \\
\hline
\end{tabular}


Table 2. Cont.

\begin{tabular}{|c|c|c|c|c|}
\hline Biopolymer Type & Soil & Assessment & Studied Parameter & Remarks (Ref.) \\
\hline \multirow{5}{*}{ Beta glucan } & \multirow{5}{*}{ Silt } & \multirow{3}{*}{ Unconfined compressive strength } & Biopolymer content & [117] \\
\hline & & & Dehydration time & [117] \\
\hline & & & Durability & [117] \\
\hline & & Splitting Tensile & Biopolymer content & [117] \\
\hline & & Direct Shear & Dehydration time & [117] \\
\hline \multirow{4}{*}{ Chitosan } & \multirow{4}{*}{ Silt } & \multirow{3}{*}{ Unconfined compressive strength } & Biopolymer content & [117] \\
\hline & & & Dehydration time & [117] \\
\hline & & & Durability & [117] \\
\hline & & Splitting Tensile & Biopolymer content & [117] \\
\hline
\end{tabular}

\section{Geotechnical Properties of Biopolymer Treated Soils}

In the current section, different aspects of biopolymer-improved soil are discussed.

\subsection{Unconfined Compressive Strength (UCS)}

The unconfined compressive strength (UCS) test is the most common test used for evaluating the role of biopolymers in soil treatment [148]. As the interaction way of biopolymer with different soil types could be entirely different, in this section, the UCS is separately discussed for each soil type.

\subsubsection{Unconfined Compressive Strength in Biopolymer-Treated Sand}

The UCS of sand treated by biopolymers is presented in this section. Figure 4 shows the maximum compressive strength obtained after air curing. Since sand does not have (or it is negligible) the ability to withstand a compressive force. Biopolymer-treated sand (1\% and $2 \%$ ) is shown in Figure 4.

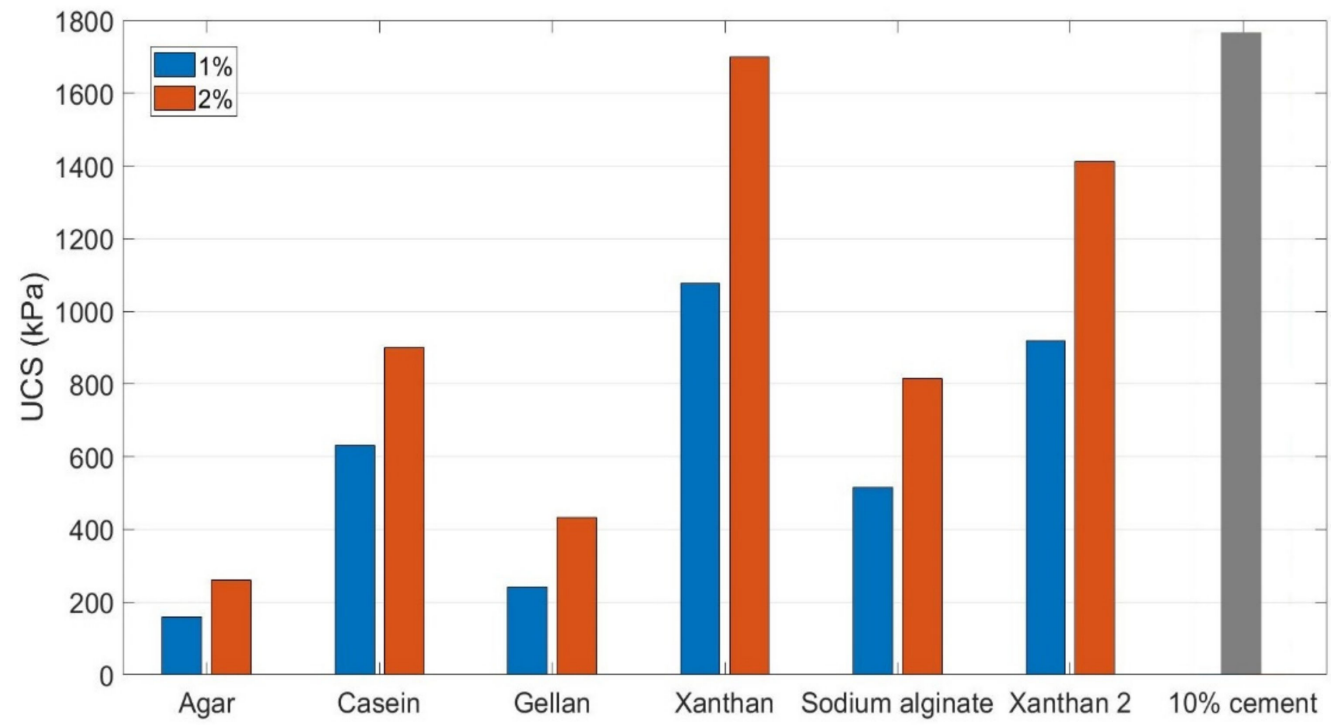

Figure 4. Biopolymer-treated sand [66,82,113,121,149-151].

As seen in Figure 4, the available results show that xanthan biopolymer can increase the UCS values up to $1700 \mathrm{kPa}$ when used to treat sand. The improved UCS value is variable depending on the type of biopolymer used. The lowest UCS value is observed when sand is treated with agar due to the repelling negative charges of both agar and sand. To improve the bond, adding a positively charged material as an intermediate agent 
would enhance the compressive strength remarkably [149]. Casein and sodium alginate showed almost similar performances, while gellan gum had lower strength compared with casein and alginate. Qureshi et al. (2017) compared the effect of xanthan gum and cement on the UCS variation of treated sand. In terms of peak UCS strength, using $2 \%$ xanthan is comparable to the strength obtained by using 10\% cement. Xanthan-treated sand gained a less ductile behavior compared to cement-treated sand by showing higher residual strength [151]. Xanthan also demonstrated a notable increase in tensile strength which is in line with compressive strength improvement; the ratio of tensile strength per compressive strength was shown to be constant regardless of the biopolymer content [121].

\subsubsection{UCS in Biopolymer-Treated Fine-Graded Soils}

Figure 5 shows how biopolymers changed the compressive strength of fine-graded soils. In the case of agar and gellan gum, UCS increased to 2500 (114.8\% growth) and $1800 \mathrm{kPa}$ (52.2\% growth) for $1 \%$ of gellan gum and agar, respectively. This higher amount of strength for gellan gum is due to the presence of multiple hydrogen and hydroxyl groups [62]. Xanthan gum has been comprehensively studied and the results are presented in Figure $5 \mathrm{~b}$. In one of the first studies using xanthan gum on clay, the compressive strength increased approximately $470 \%$ from $440 \mathrm{kPa}$ for untreated clay and $2540 \mathrm{kPa}$ for $1 \%$ xanthantreated clay [113]. Latifi et al. (2017) showed that xanthan gum is capable of improving different types of clay significantly. For example, both bentonite and kaolinite clays rendered high growth amounts after adding $1 \%$ of xanthan gum; however, this increased amount is higher for bentonite [111]. For xanthan gum, through forming hydrogen bonds and cation bridges, monomers could directly interact with electrically charged clay particle surfaces. The added biopolymer, however, lacks a tendency to approach sand surfaces with no electrical charges, thus electrostatic and hydrogen bonding will not be formed [113,152]. Also, different clay types exert different behavior when they are subject to an external material because of the various structural configurations related to the layer lattice group of clays in which oxygen ions sheets are placed on top of one another and the space between these sheets is filled with metallic cations such as $\mathrm{Al}^{3+}$ and $\mathrm{Si}^{4}$ [153].

Biopolymers improved the compressive strength of silty soils by adding a cohesive component in addition to the silt's frictional strength. Figure $5 \mathrm{~b}$ shows the compressive strength of silt stabilized by $2 \%$ of alginate, beta-glucan, guar gum, and xanthan gum. The same silt has been used for all these biopolymers. Xanthan gum gave a better performance in comparison with others, although all four biopolymers led to the enhancement in the compressive strength. Also, alginate and beta-glucan increased the UCS to almost the same level [117]. It has also been indicated that beta glucan effectively increased the compressive strength of hwangtoh soil (MH) up to $200 \%$ for $0.496 \%$ of biopolymer. The properties of beta glucan-treated soil were governed by the available cations in soil $\left(\mathrm{Na}^{+}, \mathrm{K}^{+}, \mathrm{Ca}^{2+}, \mathrm{Mg}^{2+}\right)$, charges in the soil surface as well as electrical interactions between the biopolymer [154]. Other biopolymers such as lignin have also presented good results on improving the geotechnical behavior of silt [58].

\subsection{Shear Strength}

Shear strength of biopolymer-treated soils in their dried state and cured in the environmental conditions have been presented in Figure 6. The most noticeable point is that all biopolymers enhanced the shear strength, and this improvement continued by the increase of biopolymer content. The highest growth rate is for xanthan-treated sand in terms of cohesion, which is in line with the UCS results. 


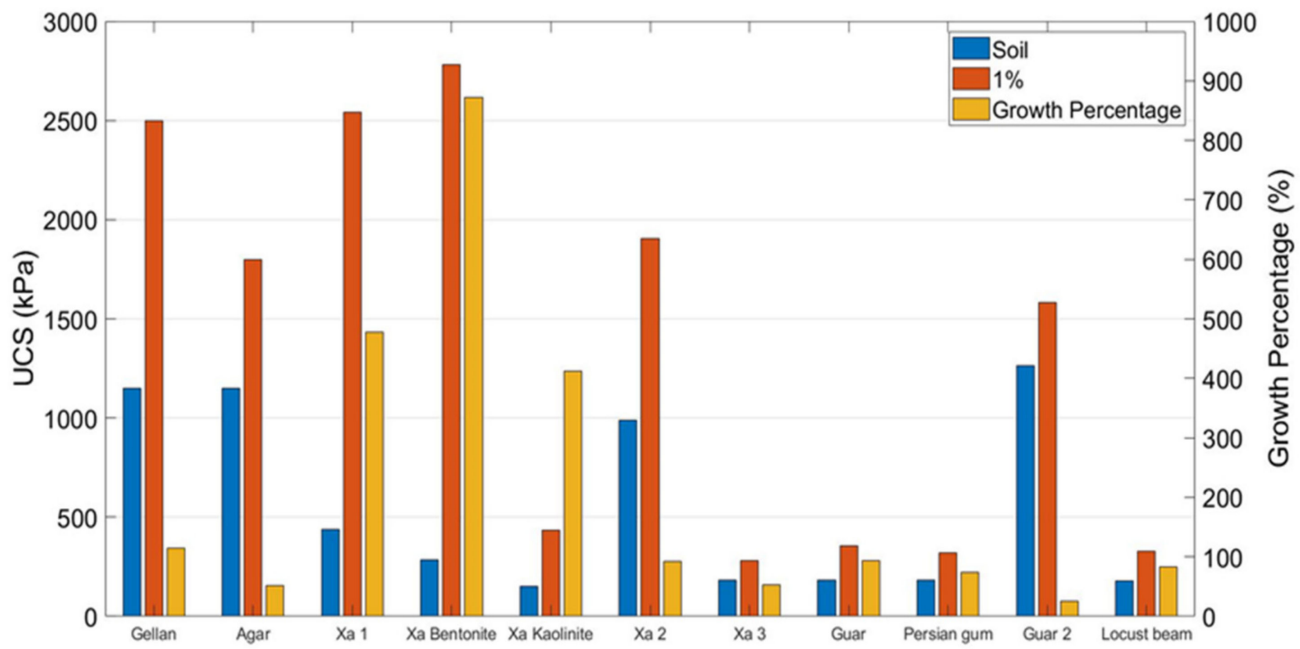

(a)

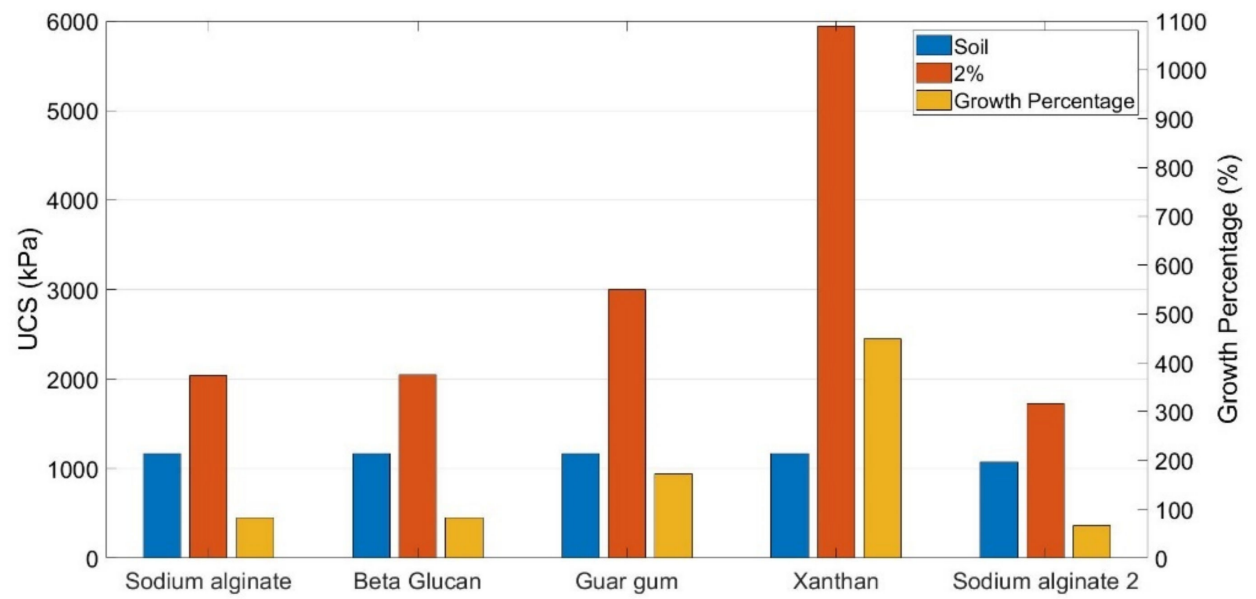

(b)

Figure 5. The effect of various biopolymers on unconfined compressive strength of fine-graded soils, (a) clay, (b) silt [62,111,113,118,130,143,155].

The shear behavior of biopolymer-treated sand is interpreted differently from the cement-treated sand; gellan-treated sand is a compound of solid grains and gellan hydrogels while the chemical structure of cemented sand is changed after the hydration process (sand and C-S-H hydrates) [156]. No chemical reaction was found between agar and sand grains, and the shear strength enhancement is due to the hydrogel generated by agar gum [157]. Also, the reason for the increase in cohesion by increasing biopolymer content is directly dependent on the biopolymer gel strength that is defined as the force needed to fracture the gel [158]; $2 \%$ xanthan gum-treated sand rendered a considerably better performance compared with gypsum-treated sand; however, $20 \%$ of gypsum led to a much larger shear strength than $2.5 \%$ xanthan [159]. For gellan-treated clay, it has been shown that gellan gum contributed to increasing both friction and cohesion values. As such, gellan gum plays an important role in the conglomeration of fine particles, this behavior is almost similar to the cement-treated clay [156]. 


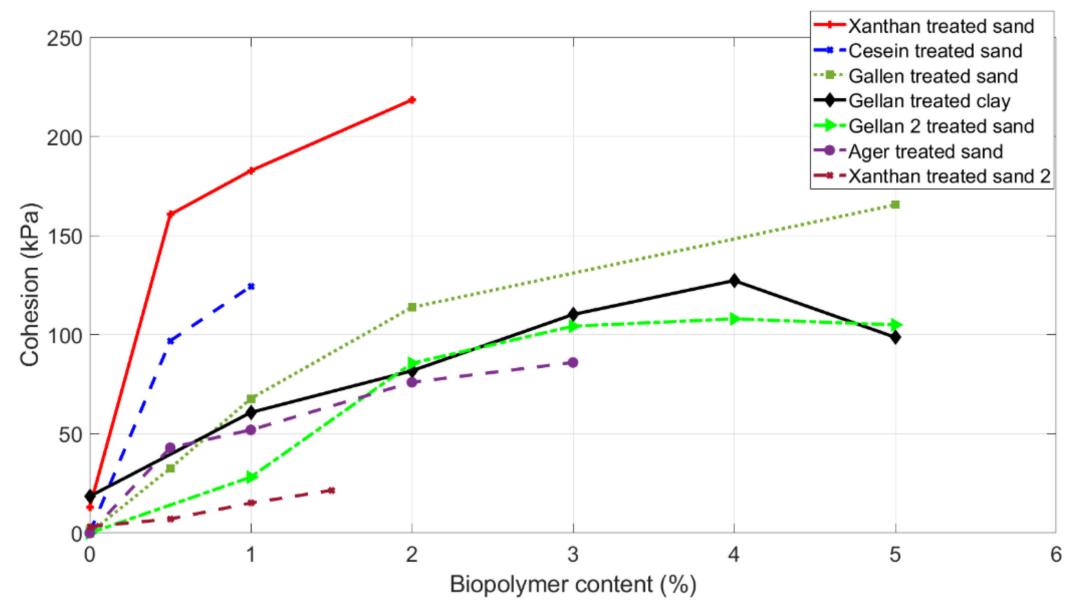

(a)

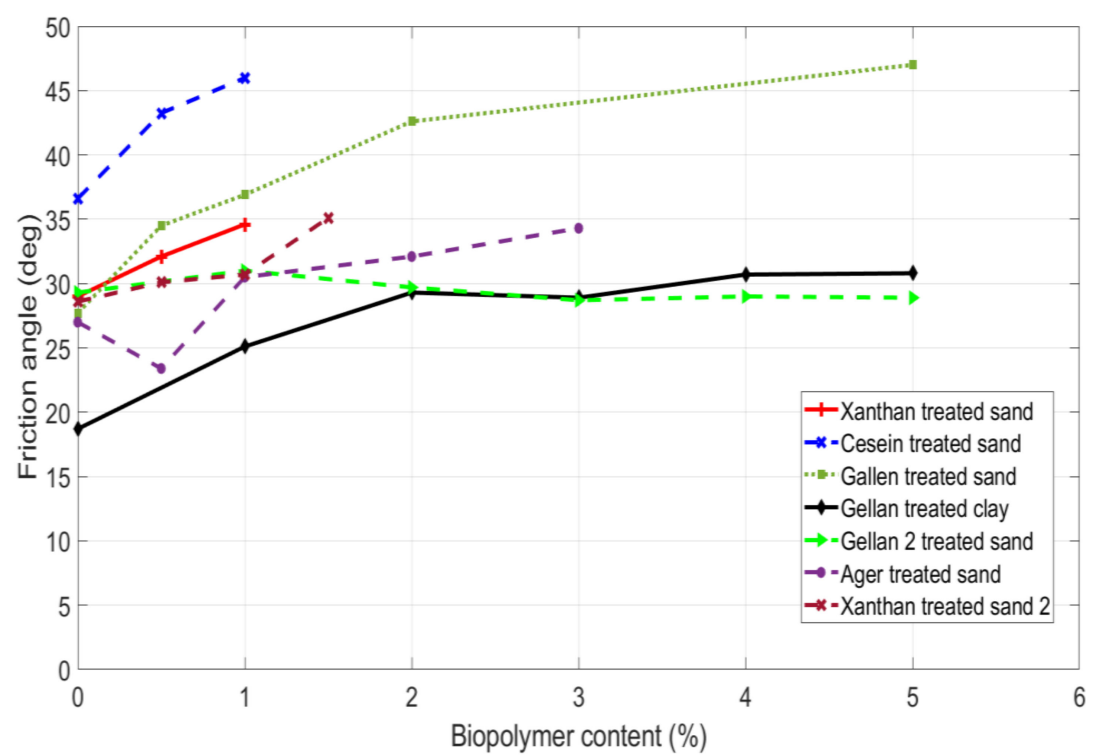

(b)

Figure 6. Variation of shear strength parameters of biopolymer-treated soils: (a) cohesion, (b) friction angle $[82,123,150,156,157,159]$.

Residual strength is the lowest amount of stress that a material can tolerate: so that, if the applied stress is lower than residual resistance, no failure will occur [160]. The residual strength of sand treated by xanthan gum was also studied [159]; the results showed that the residual strength of dried samples experienced growth for both cohesion and friction angle. This growth could be attributed to the presence of van der Waals forces between xanthan hydrogel and sand aggregates. As biotreated sand samples remain ductile after failure, their residual strength was higher than sand samples improved by $10 \%$ and $20 \%$ gypsum. Unconsolidated-undrained triaxial tests also showed that xanthan and guar increased cohesion and frictional angle of coalmine waste. Xanthan indicated better enhancement compared to guar gum after 7 days of curing [125]. Also, Zhang et al. (2021) studied dynamic characteristics of lignin-treated silt. It was reported that dynamic shear strength and modulus were effectively increased using lignin, and a decrease was observed in damping ratio [147]. The schematic form of soil with and without biopolymer treatment under direct shear testing has been presented in Figure 7. The natural soil has a low shear strength due to the lack of cohesion among soil particles. The adhesive feature of biopolymer increases the cohesion among sand particles and leads to the formation of larger aggregation [124]. 

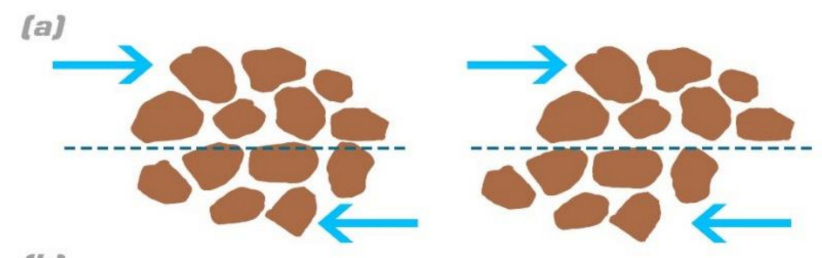

(b)
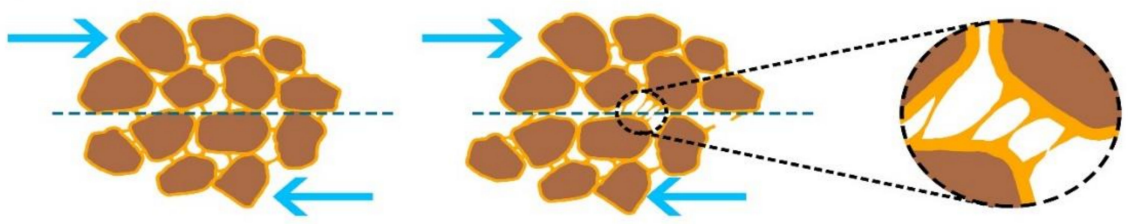

Figure 7. Schematic patterns of sand motion under direct shear testing: (a) natural sand state, (b) biopolymer-treated sand.

\subsection{Erosion Resistance}

Through the interaction between fluids (both water and wind) and soil, if the drag force of fluids overcomes both soil shear strength and gravity, soil erosion happens [161,162]. Biological clogging using microbial biopolymers plays a crucial role in reducing soil erosion by blocking the pathways of water within the pore spaces. Bioclogging leads to the formation of a less permeable layer and the reduction in water flow rate throughout the soil space [59]. It has been proven that using dextran improves the erosion resistance of soil and critical shear strength. This high erosion strength is because of increasing the cohesion and lowering the soil permeability and void ratio $[34,163]$. Under moderate and heavy rain simulation, the water erosion content decreased from $60 \%$ for untreated soil to under $2 \%$ for both beta-glucan and xanthan-treated soils, respectively [163]. Moreover, levee structures can be stabilized by employing xanthan gum against flood conditions, where stiffer soil surface with higher shear strength can be produced, thus excess pore water pressure is prevented from building up within the levee structures. This stabilizing process keeps the levee structures stable even after partial damage [127]. Water drip resistance test and water runoff test demonstrated that biopolymers can effectively change the surface properties of the sand and loose soils. However, carrageenan cannot stabilize the soil surface, and it should be used along with other biopolymers [164]. Hydraulic flume testing was utilized in order to simulate the hydraulic flow and evaluate the surface erosion resistance of biopolymer modified soil; it has been shown that adding xanthan gum resulted in $80 \%$ reduction in hydraulic erosion by making a protective jelly layer on the sand surface, and is even more effective than adding $10 \%$ of kaolinite clay to sand $[127,128,165]$.

Another serious environmental problem occurring in dry sandy soils or anywhere covered with loose soil is wind erosion. Fugitive dust, as a major consequence of wind erosion, inevitably covers roads and crops leading to the reduction in farming productivity [166]. Biopolymers potentially improve the soil resistance against wind erosion by forming a firm crust over the sand surface, not even one crack was observed after a wind tunnel test on biopolymer treated samples (Figure 8). Xanthan gum and guar gum gave better performance compared to carrageenan and modified starch [120,166,167]. Moreover, the durability of xanthan and chitosan-treated soils is expected to be effective, at least up to two weeks against wind erosion $[166,168]$. In a relatively large-scale project aimed at dust mitigation for 90 days, synthetic polymers demonstrated better efficiency in the reduction of dust amount in comparison to guar gum as a biopolymer [169]. In terms of mine tailing stabilization, the weight loss of mine tailings treated by both xanthan and guar gums was smaller than water-treated sample; however, after five cycles of wetting and drying, the reduction was greater than the first cycle due to microstructural damage, wet-dry cycles, and ultraviolet (UV) radiation [170]. 


\author{
Before wind \\ erosion
}

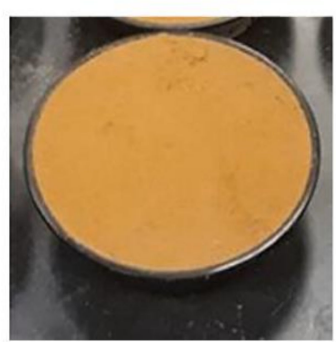

After wind

erosion

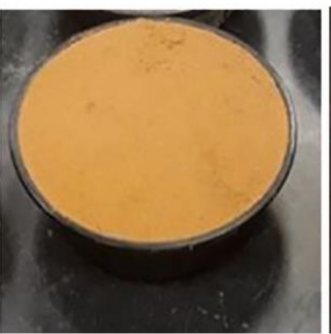

Crust formed

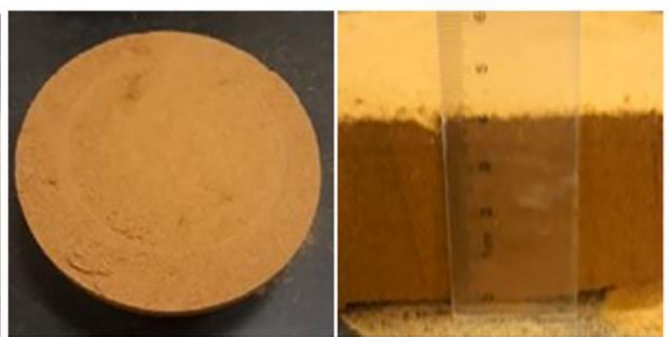

Figure 8. Crust formation of sand treated by sodium alginate biopolymer [145].

Figure 9 shows how soil resists wind erosion in both natural state and biopolymertreated soil. As seen, a set of forces including resistant forces and driving forces exist during wind erosion. Driving forces consist of aerodynamic drag $\left(\mathrm{F}_{\mathrm{d}}\right)$ and aerodynamic lift $\left(\mathrm{F}_{\mathrm{L}}\right)$, which try to disconnect the soil grains from the soil mass. Resistant forces include the gravity force $\left(\mathrm{F}_{\mathrm{g}}\right)$ and the interparticle cohesive force $\left(\mathrm{F}_{\mathrm{i}}\right)$, that prevent soils from being eroded $[167,171]$. In the natural state of the sand, $F_{g}$ is defined as the weight of one soil grain. Typically, $F_{i}$ has a small value because of the low amount of interaction among soil particles so that the airflow is easily capable of eroding the soil. When the biopolymer is added to the soil mass and after drying, the biopolymer hydrogel directly interacts with the soil by coating the soil particles and forming strong chemical bonds, which leads to the formation of a network consisting of soil grains and biopolymer. In this condition, the $F_{g}$ is the weight of the whole soil mass so that it has an amount much larger than that in the natural state. Also, the inter-particle force is significantly increased because of the biopolymer network. The additional resistant force results in a higher total restraining force than the driving force, which remains unchanged in both biotreated soil and natural state.
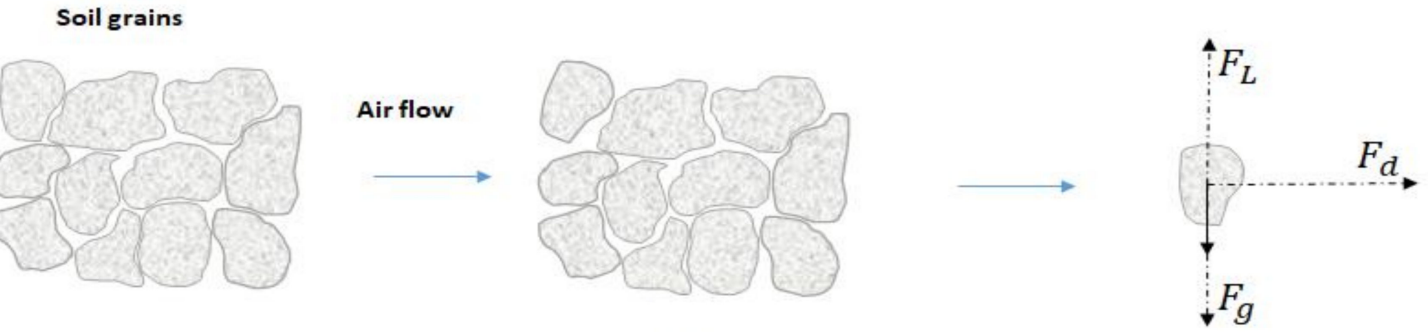

(a)
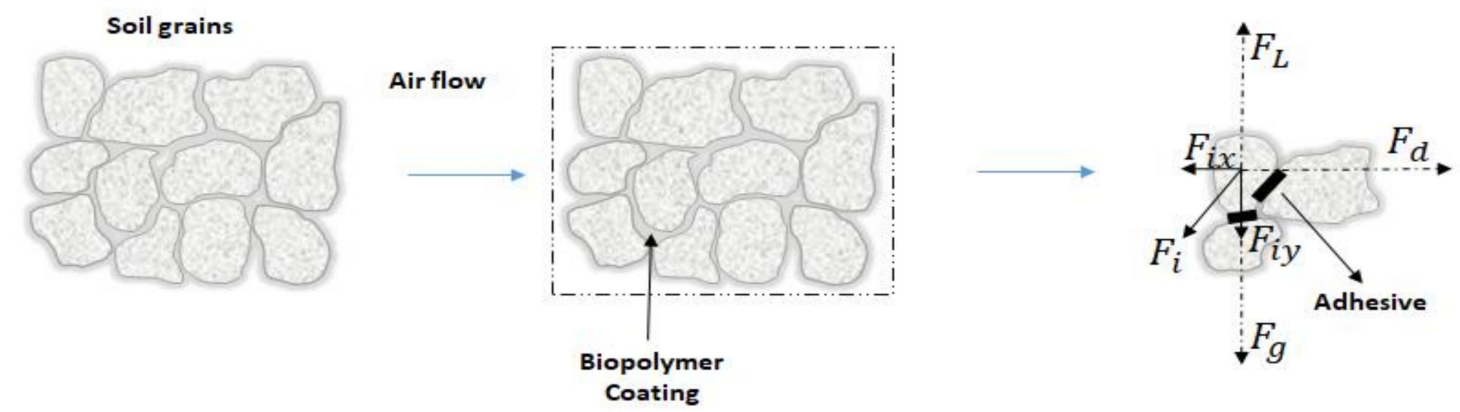

(b)

Figure 9. Mechanical trend of soil resistance against wind erosion: (a) sand in natural state, (b) biopolymer treated sand [154]. 


\subsection{Atterberg Limits}

Atterberg limits are considered a fundamental concept of soil consistency in soil classification. Atterberg limit tests define the boundaries where clay and silt go through four different physical changes (solid, semi-solid, plastic, and liquid) by moisture content variation [172]. Figure 10 demonstrates how different biopolymers can affect the Atterberg limits of soils. As seen, almost all biopolymers have an increasing effect on the liquid limit (LL) (Figure 9a) and plastic limit (PL) (Figure 10b). Also, the more the biopolymer content, the higher the PL and LL. However, the growth trends of LL and PL vary based on the biopolymer type and soil characteristics; this difference of growth rates results in having both decreasing and incremental trends for PI via the increase in biopolymer content. The enhancement of LL for beta-glucan treated clay is due to the high-water adsorption of beta-glucan, a linear correlation to approximate the PI based on beta-glucan content has also been presented [154]. Lignin-treated silt experienced a reduction in PI after rising the amount of lignin, while PL and LL were increased; due to the quick cation exchange between silt and lignin, the lignin coated soil particles and formed a strong network by filling the pores [173].

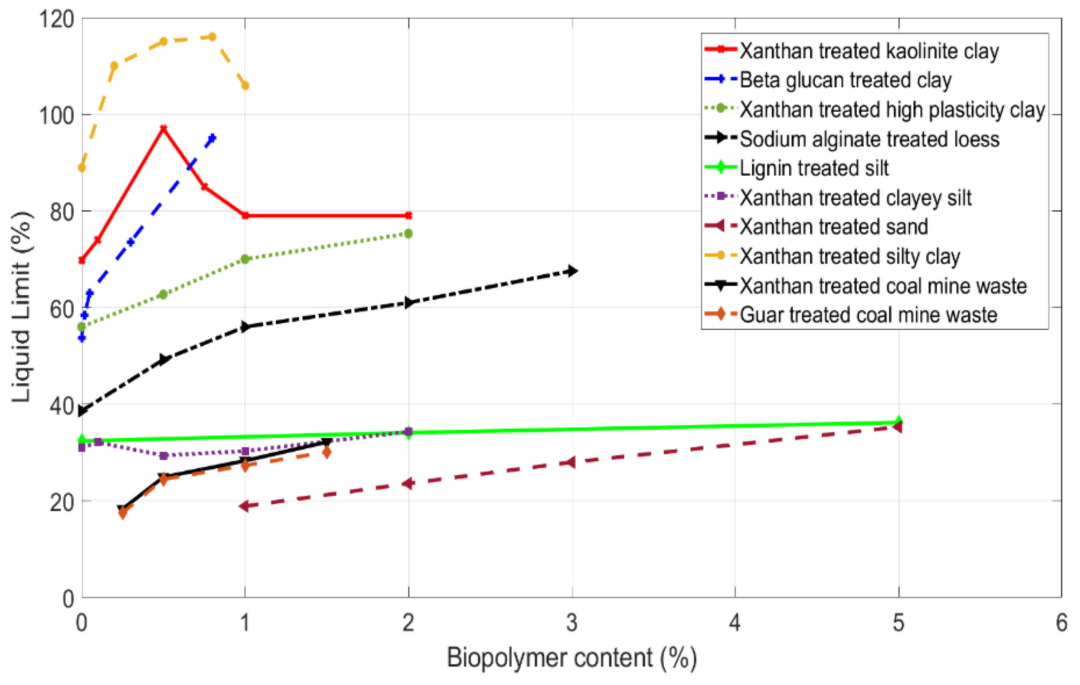

(a)

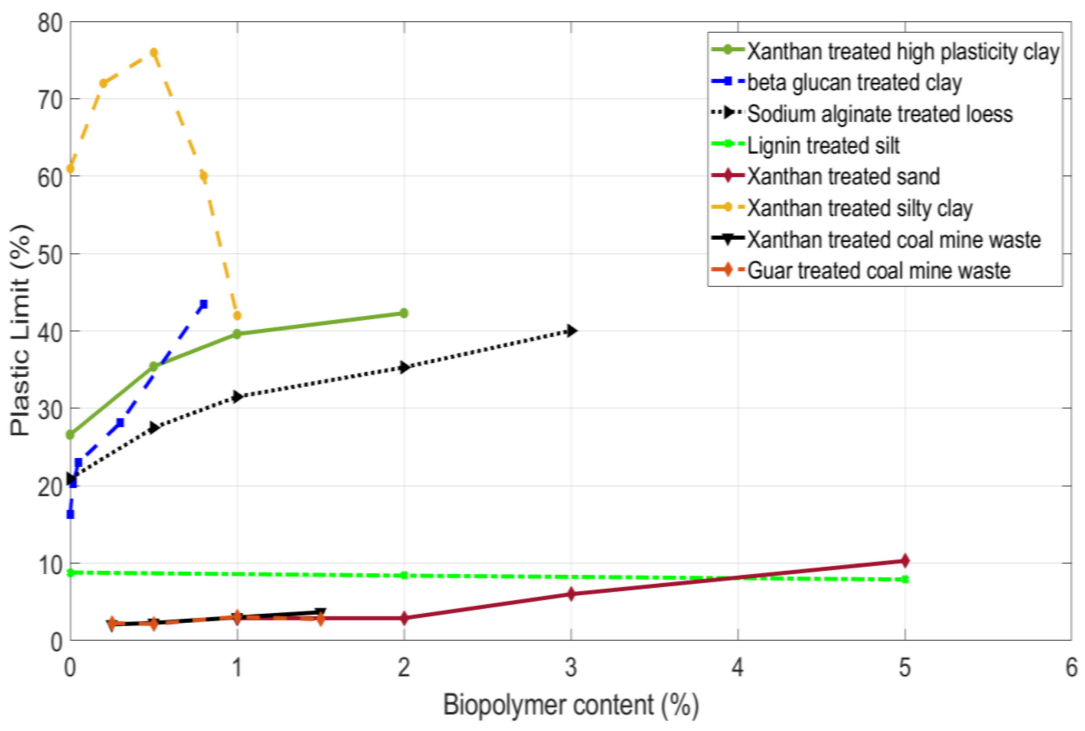

(b)

Figure 10. Cont. 


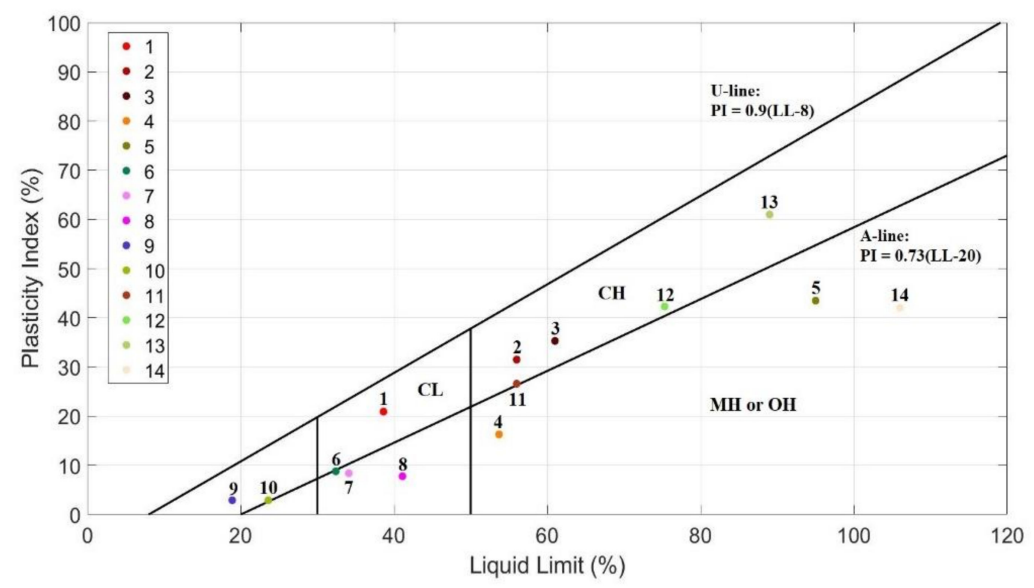

(c)

$$
\begin{array}{cccc}
\multicolumn{4}{c}{\text { Details of the numbered coordinates }} \\
\text { Loess } & \mathbf{8} & 12 \% \text { lignin-treated silt } \\
1 \% \text { sodium alginate-treated loess } & \mathbf{9} & 1 \% \text { xanthan-treated sand } \\
2 \% \text { sodium alginate-treated loess } & \mathbf{1 0} & 2 \% \text { xanthan-treated sand } \\
\text { Korean residual soil (KRS) } & \mathbf{1 1} & \text { High-plasticity clay } \\
0.8 \% \text { beta glucan treated KRS } & \mathbf{1 2} & 2 \% \text { xanthan treated high-plasticity clay } \\
\text { Silt } & \mathbf{1 3} & \text { Silty clay } \\
\text { 2\% Lignin-treated silt } & \mathbf{1 4} & \text { 1\% xanthan treated silty clay }
\end{array}
$$

Figure 10. Variation of Atterberg limits by adding biopolymer, (a) liquid limit, (b) plasticity index, (c) plasticity chart $[102,111,120,123,130,138,141,161]$.

For soft marine soil, it was shown that LL and PL had a tendency to increase with the increase in biopolymer to soil content, which is a result of forming hydrogel in pore space and direct chemical interaction with charged clay surfaces [134]. For sand treatment by xanthan gum, the hydrophilic feature of xanthan adsorbs water which provides the conditions to form xanthan hydrogel around and between sand particles, so that the behavior of soil becomes plastic and cohesive. This good property of treated sand improved the shear strength and wind erosion resistance of cohesionless sand [151]. Chang et al. (2019) studied the soil consistency characteristics for different kinds of clay mixed with sand employing xanthan biopolymer. The presence of sand in the clay reduced the value of LL and plasticity. Xanthan gum is able to transform the clay state from liquid to plastic for the contents more than $8 \%$ [134]. Also, trends for LL variation were not the same for different clay types. Xanthan-treated montmorillonite clay indicated a decreasing variation by the increase in xanthan content which is a consequence of the higher xanthan tendency to react with montmorillonite particles instead of pore fluid. The kaolinite-sand mixture initially experienced an increase in LL, then it decreased to an almost constant value; this shows xanthan simultaneously interacts with kaolinite particles and forms a hydrogel in the pores [137].

The relationships of the LL and PI for biomodified soils are presented in the plasticity chart (Figure 10c). It can be seen that adding sodium alginate into loess resulted in moving from the area of medium plasticity to high plasticity. This graph also shows that other biopolymer-treated soils tend to generate greater plasticity. This variation is directly related to the amount of surface charge and the size of clay particles in which biopolymers can be effective, in terms of hydrogel formation and electrical interactions. The cohesionless sand develops low plasticity after the addition of $1 \%$ xanthan gum. This improvement for desert sand is in accordance with achieving high erosion resistance as well as controlling soil degradation and desertification.

\subsection{Compaction Test}

The compaction behavior was different for various biopolymer-treated soils. In the case of beta glucan-treated KRS (Korean residual soil), both optimal moisture con- 
tent (OMC) and maximum dry density (MDD) increase with increasing biopolymer content [154], whereas the MDD of biotreated collapsible soil by guar and xanthan gum reduced compared with untreated soil; this reduction was related to the lightweight collapsible soil grains which allowed them to move around because of the effect of solution viscosity [174]. For lignin-treated silt, the MDD tends to increase with increasing lignin content, but for lignin contents higher than $12 \%$, the MDD reduced because $12 \%$ was reported to be the optimal biopolymer content, thus the biopolymer did not act as a stabilizer. In other words, it can be said that all the pores were filled by the biopolymer, and the larger biopolymer content leads to the accumulation of lignin and the reduction in soil density. OMC was also affected by the lignin in such a way that OMC would slightly decrease compared with natural silt: it should be noted that this variation can change depending on the biopolymer and soil characteristics [58,173].

For sand treated by xanthan gum, it has been reported that the MDD and OMC behaviors were symmetrical such that $1 \%$ biopolymer caused the highest MDD and lowest OMC to be reached, then by increasing the biopolymer content, MDD reduced and OMC started to increase. The initial growth in MDD was due to the lubrication effect of biopolymer until 1\%, while for higher content, xanthan showed a negative effect so that a swelling behavior of the treated soil was observed [151,175]. The xanthan-treated clay showed different behavior in comparison to the biomodified sand. It has been shown that MDD reduced when $3 \%$ xanthan was added to the clay and OMC increased [114]. As most of the biopolymers used for soil improvement purposes are hydrophilic and tend to absorb water, the moisture content of the biopolymer-treated soil should be strictly controlled to achieve the appropriate degree of compaction, especially at the construction site. To have a comparative outlook, it should be mentioned that increasing the content of traditional and calcium-based traditional stabilizers typically leads to the reduction in MDD and the increase in OMC [173].

\subsection{Durability}

The variation of geotechnical properties of soil treated by different polymers under different environmental conditions including cycles of wetting and drying as well as freezethaw, and decomposition has always been a concern [176]. As most biopolymers employed in soil improvement are soluble in water, exposure to water would surely affect their performance during wet-dry cycles. After the first dehydration of gellan-treated sand, once the dried samples were subjected to water, the dehydrated gel began to absorb water and undergo volumetric expansion. Then, the outer parts of the gel are slightly detached from the main gellan gel. This process leads to a reduction in the compressive strength for the wet sample compared to the dried state. During redrying, dissociated gellan gum fibrils attach to the main body again due to a lowering in moisture content. The wet and dry cycle leads to the detachment and attachment of some minor parts of the gel which will result in weakening of the biotreated sample and incomplete recovery of all hydrogel. Repeating more cycles causes the compressive strength to gradually reduce and converge to a specific level. Moreover, the stiffness follows a similar trend and shows a more ductile behavior than traditional binders such as cement and lime which experience a brittle collapse after a limited number of wetting and drying cycles [177].

The durability of treated soils has also been studied using xanthan gum through various experiments. Slake durability tests indicate that xanthan gum is capable of improving slake durability index to a value that is comparable with cement-treated sand. A higher amount of biopolymer led to better performance against wet-dry cycles. Although xanthan gum adsorbed water which subsequently reduces the strength, the hydrogel remained available for the subsequent cycles, that is why some proportions of xanthan biopolymer performed better than cement [151,178]. As for decomposition, 750 days of curing the Red Yellow soil enhanced by xanthan gum without wetting and drying slightly increased the compressive strength and stiffness in comparison to 28-day cured samples. This procedure was also the same for curing time of 21 and 63 days for sand and clay treated by xanthan 
gum which could be attributed to the high stability of xanthan gum under temperature variation and dehydration [113]. In addition, keeping samples for 30 days under real conditions with different temperature, humidity, as well as wet-dry cycles indicated a considerably better performance for xanthan treated sample compared with untreated silt [117]. However, it has been presented that guar gum rendered a greater efficiency than xanthan gum in water erosion after five wet-dry cycles, whereas carrageenan showed poor performance in this regard and disappeared after the second cycle [167]. Furthermore, xanthan gum-treated silt performed much better than virgin high plasticity silt after 12 days of freezing and thawing cycles [118]. The results in the literature demonstrate that the durability of biopolymers in long-term applications requires more attention in order to explain how they can be affected by various environmental and destructive circumstances such as wetting and drying cycles, freezing and thawing cycles, microorganisms, and UV attack $[179,180]$.

\subsection{Pavement Application}

Currently, there are limited studies on the role of biopolymers in the enhancement of pavement layers. The California bearing ratio (CBR) and resilient modulus tests are parameters of evaluation for pavement layer stabilization. A considerable increase has been reported in the resilient modulus of silt and clay by the addition of sodium alginate. Up to $2 \%$ for clay and $4 \%$ for silt, the trend was increasing, then a declining trend was observed for larger proportions. The better performance of sodium alginate in clay enhancement is due to the existence of sufficient free cations tending to react with an anionic biopolymer and forming a gelling structure, and filling the pores; while the available cations may not be enough to turn biopolymer into the gel form [181]. Sodium alginate also has significant efficiency in enhancing the unsoaked CBR of dune sand [66]. A very low amount of xanthan $(0.4 \%)$ reduced $36 \%$ of the required thickness for the unstabilized sand

Resilient modulus (RM) also increased when lignin, up to $12 \%$ (optimal content), was added in silt which was in line with the UCS results [58,182-184]. This coincidence was the same for adding protein-based biopolymers including casein and sodium caseinate into the dune sand [82]. Thus, it can be seen that the variation of pavement parameters (RM and CBR) for biopolymer-treated soil is in line with the UCS results. The criteria of pavement design consider a minimum amount for maximum compressive strength obtained from the UCS test; this standard value is determined based on specific conditions in different countries. The feasibility of using xanthan gum for sub-base stabilization as well as road shoulder construction has been investigated and compared with cement and geopolymers. The results showed that the UCS of xanthan-treated silty sand passed all design criteria in terms of the required UCS. Also, the higher ductility of xanthan-treated soil was a positive impact if compared against cement and fly ash [122]. However, more studies are still required to comprehensively investigate how different types of biopolymer behave under various environmental and loading conditions.

\section{Factors Affecting Geotechnical Properties of Biopolymer-Treated Soils}

Using biopolymer binders for soil improvement should be applied in optimal conditions because various parameters can influence the biomodified soil characteristics. In this section, the important factors in geotechnical aspects of stabilized soils have been critically evaluated. As the experimental conditions for these results vary in many aspects, such as the soil types and curing conditions, they cannot simply be judged by the same standards, hence specific understanding of each test condition or consideration is important.

\subsection{Biopolymer Concentration}

Biopolymer content is usually the first parameter investigated in many studies of biopolymer-treated soils to develop an understanding of how the soil would eventually react to the additives. Concentration is mostly demonstrated based on the biopolymer ratio to the soil mass. In the dry state, the required biopolymer content for reaching a 
specified strength is much lower than that of cement or other traditional stabilizers [150]; however, lignin needs a higher quantity compared with other biopolymers $[58,185]$. The untreated soil strength has often been less than biopolymer-treated soil regardless of biopolymer content. The effect of biopolymer content on the unconfined compressive strength for biomodified soils in their dry states has been presented in Figure 11. As is the case for treated sands, an increasing trend can be observed for almost all samples when the biopolymer content increased, while this observation does not seem to apply to xanthan that tends to reduce by adding biopolymer higher than $2 \%$ by weight. When an excessive amount of xanthan is added to the soil, the interaction of sand and hydrogel is reduced by concentrating in localized places. Protein based biopolymers (casein and sodium caseinate) continuously enhanced the sand compressive strength significantly up to $5 \%$ biopolymer content. Casein-treated sand indicated a higher growth rate in compressive strength in comparison to agar and gellan-treated sands $[66,82,149-151,186]$.

The comparative results of silt-treated soils are presented in Figure 11b. The procedure is also similar to coarse-grained soil improvement and it was observed that all biopolymers improved the UCS. It was shown that UCS increases significantly when biopolymer, such as xanthan or beta-glucan, is added to the soil. It was observed that considerable improvement takes place until an optimal level is reached, after which its rate of improvement reduces e.g., lignin-treated silt. It is noteworthy that the respective optimal amounts for (a) lignin to treat low-plasticity silt is $12 \%$, (b) xanthan to treat bentonite and kaolinite clays is $1 \%$ and $1.5 \%$, respectively, (c) guar gum to treat silt with low plasticity is $1 \%$, and (d) xanthan on lowplasticity silt is $2 \%$. Higher lignin contents led to the excessive local concentration within the soil pores so that the reduction in frictional resistance would be a consequence of this effect [173]. Also, Soldo et al. (2020) observed that the increase in the treated soil's Young's moduli increases in a similar fashion as the optimal concentration for xanthan and guar gum for improving UCS [117]. However, for biopolymers including beta-glucan and casein, the optimal content cannot be accurately specified due to the variable trends of results. These optimum values for some mixtures of biopolymer-soil indicate that the optimized quantities should be rigorously investigated for more types of biopolymer-treated soils to pave the way for using biopolymers as alternative sources to traditional materials.

Sodium alginate and xanthan reduced the initial hydraulic conductivity of silty sand, and higher biopolymer contents caused lower permeability, because of the high tendency of xanthan gum to adsorb water and clay minerals [187]. Using a sufficient concentration of casein has also satisfied the required UCS for typical (non-fired) adobe blocks (UCS $\geq 1.32-1.56 \mathrm{MPa}$ ), as well as traditional adobe block construction (UCS $\geq 1.18 \mathrm{MPa}$ ) [107,188-190]. Although, the minimum UCS required for fired block (UCS $\geq 10.3 \mathrm{MPa}$ ) is larger than the UCS obtained for casein-treated soil [191]. Besides, it has been indicated that the higher the biopolymer content, the higher the shear strength. In terms of improving erosion resistance, the increase in adhesive content also resulted in better performance.

\subsection{Moisture Content}

Water susceptibility is one of the main problems of using biopolymers in soil improvement because dehydrated biopolymer tends to absorb water and then swell. This is due to the hydrophilic property of most biopolymers that results in weakening the geotechnical behavior of treated soils [192]. Nevertheless, the mechanical strengths of bio-improved soil in saturated conditions are mostly higher than untreated soil samples. Agar and gellan-treated sand under submerged conditions showed behavior that was independent of time, with the compressive strength remaining constant with time. This fixed strength can be explained by the hypothesis that water content governs the mechanical properties of these thermogelatin-treated soils rather than time. Therefore, if high UCS values are desired in dry conditions, reduction of water is the best option [62]. 


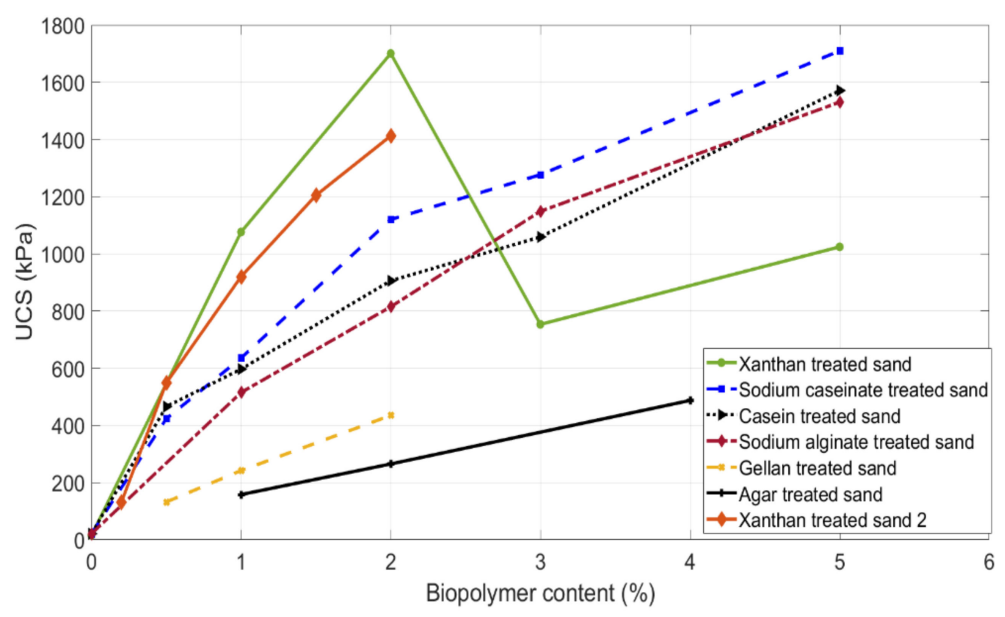

(a)

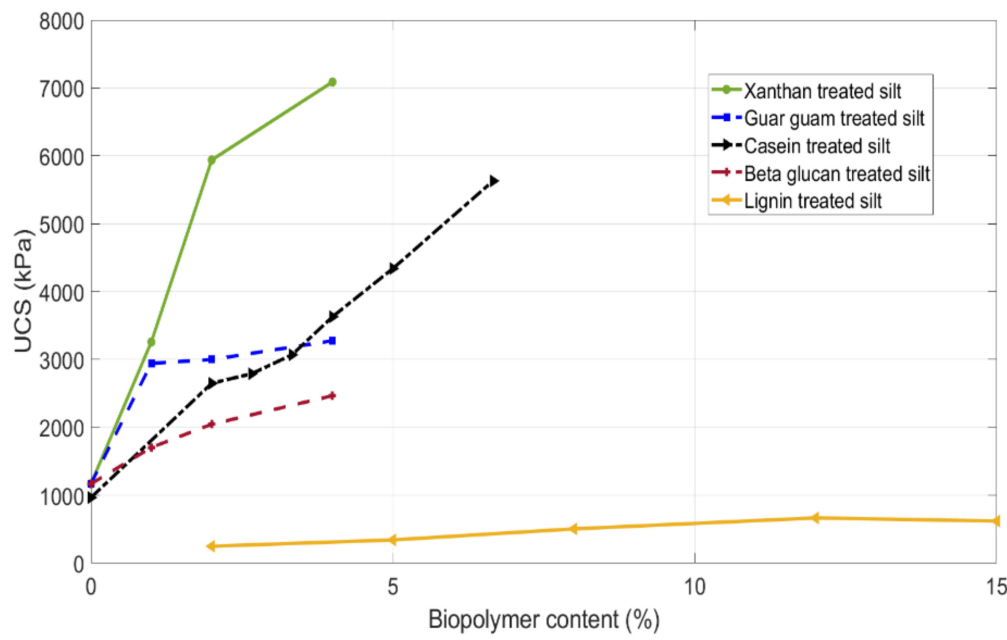

(b)

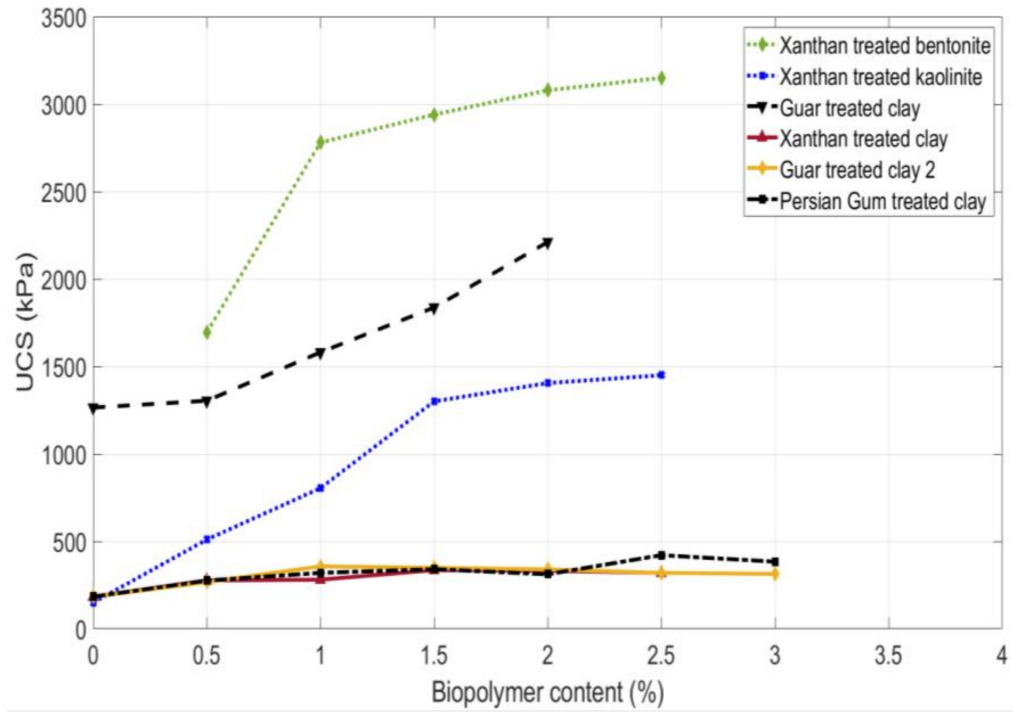

(c)

Figure 11. Effect of biopolymer content on compressive strength of soils (a) biopolymer-treated sand, (b) biopolymer-treated silt, (c) biopolymer-treated clay [56,70,94,97,103,135,136,138,161]. 
The geotechnical features of treated soils with the same amount of moisture could be different in initial and submerged states. Resubmerging the samples after drying provides the conditions for biopolymers to absorb water and return to their hydrogel state, and the water content would often be less than the initial state [62,107]. For gellan gum, the lower results after resubmergence can be explained by the fact that gellan gum is not recoverable after one dehydration [150]. Casein performed better in the wet state than some biopolymers such as beta-glucan, xanthan gum, gellan, and agar. The reason for the poor efficiency of these biopolymers is that the strengthening procedure of polysaccharides is mostly governed by hydrogen bonding and hydrogel behavior $[15,107]$.

The most fundamental concern of collapsible soils is related to being saturated. Adding xanthan gum improved this drawback significantly by increasing the wet shear strength [174]. In addition, loess soil, which is unstable for undergoing the effect of water and rainfall, was improved by adding sodium alginate, which helped the loess to stay totally in shape after a long period of soaking, while the non-treated loess was lost completely after $30 \mathrm{~s}$. Therefore, sodium alginate could prevent a loess slope from becoming saturated and enhance slope stability [144]. In terms of shear strength, $2 \%$ xanthan gum increased the cohesion and total shear strength of the soil, while the friction angle was reduced compared to untreated sand. At the initial condition, the hydrogel bond strength is responsible for the increase of shear resistance because, at this stage, there is still no direct chemical interaction between biopolymer and the host soil. Meanwhile, in the resubmerged state, the residual biofilm close to sand particles along with hydrogel helps to increase the shear strength of the sand [159].

Figure 12 demonstrates how moisture delays the formation of direct contact between the clay surface and biopolymer. The presence of water and biopolymer together means more time will be needed for biopolymer-treated soil to dry, which can be attributed to the hydrophilicity and water retention of biopolymers [193]. More importantly, the initial moisture content is usually taken as OMC obtained from the compaction test that is not necessarily the best choice for the highest compressive strength. For a clay treated by $1 \%$ xanthan gum, $4 \%$ greater water content than OMC of treated samples led to a more prominent stress-strain behavior. Given this, there could be an ideal initial moisture content for each biopolymer-soil mixture [131].

\subsection{Temperature}

Elevated temperature is a parameter that can affect the mechanical behavior of a biopolymer. The most affected biopolymer group used in soil improvement is related to thermogelatin biopolymers including agar and gellan. Thermo-gelation biopolymers tend to dissolve and are suspended in hot water (between 80 and $90{ }^{\circ} \mathrm{C}$ ); following that, they coagulate into a gel state after the temperature decreases to below $50{ }^{\circ} \mathrm{C}$ [194]. This thermal process provides the conditions to obtain the highest efficiency of these biopolymers, which is why agar and gellan resulted in higher compressive strength of the soil compared to the biomodified soil without thermal treatment, as well as higher stability in submerged conditions [62]. Air-dried curing $\left(20^{\circ} \mathrm{C}\right)$ caused the formation of a solid layer in the external part, which then led to a delay in curing the inner part of the sample. A similar sample cured at $40{ }^{\circ} \mathrm{C}$ experienced a uniform cementitious process on both external and internal sections. Therefore, drying at $40^{\circ} \mathrm{C}$ gave a greater performance compared with air-dried conditions [124].

Other types of biopolymer have also presented a similar behavior when the biopolymertreated soil is subjected to curing at different thermal conditions, in the way that raising the temperature to an optimal value would be quite beneficial for improving the strengthening process. Then, temperatures higher than the optimal value led to a loose structure, and sometimes higher temperatures led to decomposition of the biopolymers because of weakening the bonds and connections amongst biopolymers and soil grains became weaker $[66,82,115]$. For example, temperatures more than $60^{\circ} \mathrm{C}$ for casein-treated sand caused the compressive strength to fall to a low of $48 \%$ which was similar to the conse- 
quence of decomposing casein in amino acid [82]. According to the literature review, the optimal temperature for different biopolymer-treated soils can be expressed as follows: $45^{\circ} \mathrm{C}$ for sodium alginate-treated sand, $60^{\circ} \mathrm{C}$ for both casein and sodium caseinate-treated sand, and $60^{\circ} \mathrm{C}$ for beta glucan-treated silt $[66,82,115]$.

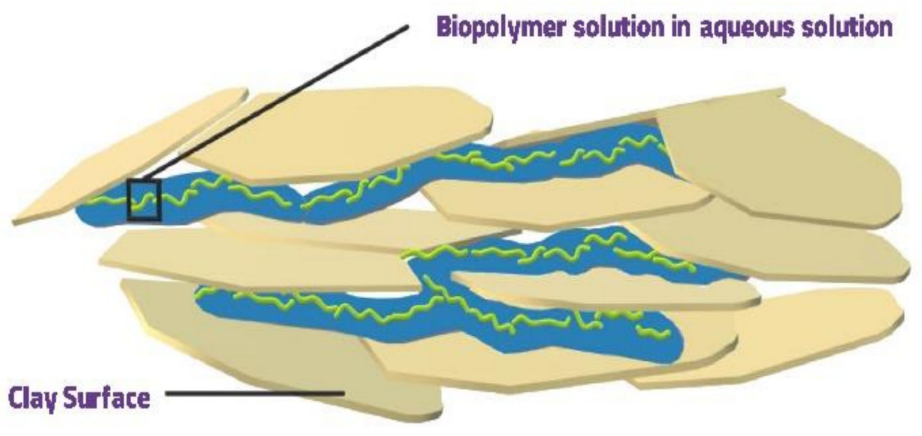

(a)

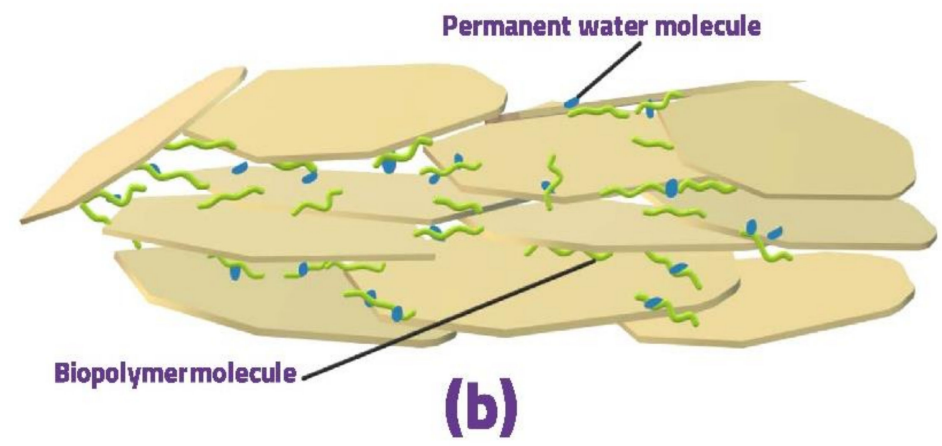

Figure 12. Moisture effect in interaction of biopolymer with clay sheets (a) moist biotreated sample, (b) dried biotreated sample [121].

\subsection{Dehydration Time}

After preparation of the biopolymer-soil mixture, hydrophilic biopolymers try to absorb water and form hydrogel networks within the soil pores; thus, it is the inherent geotechnical properties of the host soil that govern the eventual strength of the improved soil. However, it has also been shown that some biopolymers can play a role in increasing the initial compressive strength of soil $[80,177]$. Moreover, it is also not feasible to perform unconfined compressive tests on biotreated sand when it is still wet because the biopolymer has not effectively attached to the soil particles [66,82]. It is thought that curing duration is directly related to the moisture content, therefore, elapsed time provides the hydrogel the opportunity to lose water and dehydrate.

Figure 13 demonstrates the optimal curing time needed for each type of biopolymertreated soil. In this chart, the optimal time is considered the number of days that are needed for a biopolymer-treated soil to obtain greater than $80 \%$ of its final strength. As shown, based on the biopolymer, the optimal curing time could be different for various cases because of the biopolymer type as well as the soil type. For instance, the optimal time for different types of clay treated by xanthan gum is usually around 28 days, while this is less than five days for xanthan-treated silt [111,114,117,118,133]. Moreover, the higher amount of biopolymer could also increase the dehydration process, because more water would be absorbed by the biopolymer [195]. 


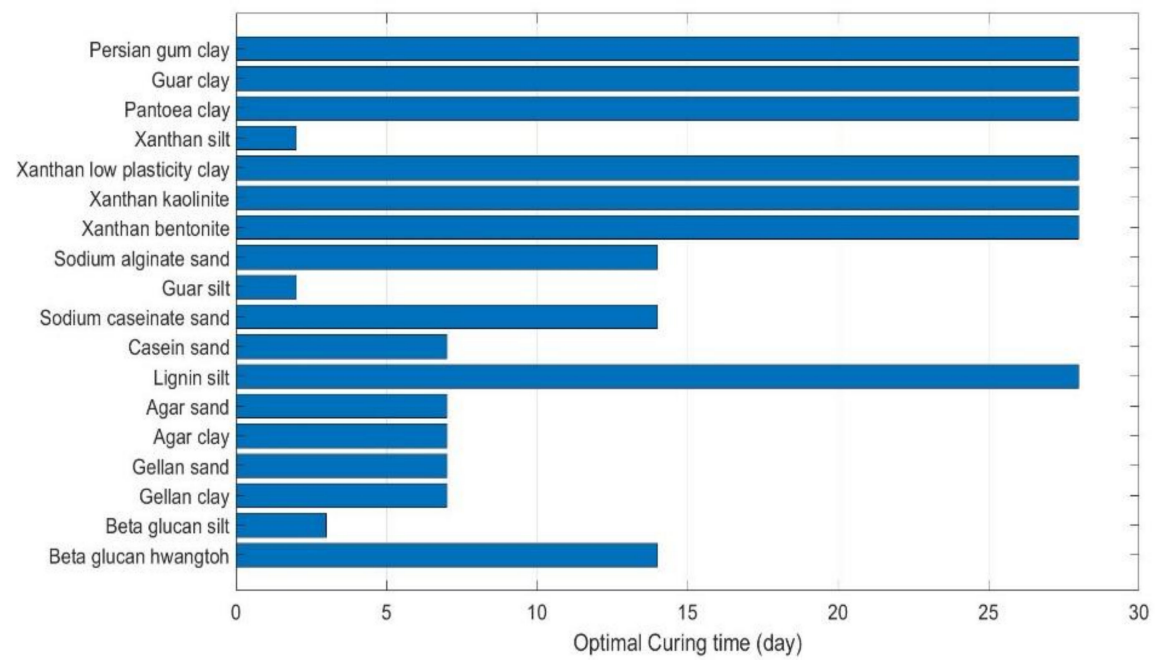

Figure 13. Optimal time required for each biopolymer-treated soil $[58,62,66,82,111,115,130,133,138$, $158,174,196,197]$.

\subsection{Effect of Adding Fiber}

Adding fiber to soils offers a solution to increasing the ductility (in case of brittle behavior) and enhancing the swelling behavior of clay. This subject has still not been comprehensively investigated, however, some research indicated that adding fiber was effective in soil treatment. Both plant-based and animal-based fibers can be applied regarding this matter. Date palm fibers along with xanthan gum were used to enhance dune sand. Results showed that fiber increased the vane shear strength of the treated sand at a low concentration of xanthan, while high xanthan contents (2\%) experienced almost the same strength with and without adding fiber [175]. The addition of sheep wool along with sodium alginate showed significant growth in the compressive strength performance of cohesive soil from 2.23 MPa for natural soil to 4.44 MPa for reinforced biotreated soil. It should be noted that wool amount should be limited to keep the high strength. Also, the flexural strength was increased by $30 \%$ using a mixture of wool and alginate [196].

\section{Potential Geotechnical Applications of Biopolymer-Treated Soil}

As shown, biopolymers can improve different soil characteristics so that they can be useful in various geotechnical applications, some of which are discussed in this part of the paper.

\subsection{Base and Sub-Base Stabilization}

A successful pavement design satisfies the minimum structural criteria in terms of shearing resistance, excessive deflections, and reduction of permanent deformations, such that soil binders are used to ameliorate problematic soil properties and reduce the required thickness of layers. When it comes to selecting a stabilizer, the following parameters are of the highest importance: soil type, soil improvement type, required durability and strength level, cost, and environmental considerations. General employable materials for pavement improvement are cement, lime, lime-cement blends, bitumen, granular materials, and chemical products. A comprehensive geotechnical investigation must be undertaken before and after stabilization to assess how a binder changes soil property. These geotechnical tests include CBR, UCS, repeated load triaxial test, wheel-tracking test, indirect tensile modulus, flexural modulus, capillary rise test, vertical saturation test, erodibility test, and leaching test [197].

Currently, there are limited studies on the role of biopolymers in the enhancement of pavement layers. CBR and resilient modulus tests are parameters of evaluation for pavement layer stabilization. A considerable increase has been reported in the resilient modulus of silt and clay by adding sodium alginate. Up to $2 \%$ for clay and $4 \%$ for silt, the 
trend was increasing, then a declining trend was observed for larger proportions. The better performance of sodium alginate in clay enhancement is due to the existence of sufficient free cations tending to react with an anionic biopolymer and form a gelling structure and filling the pores; while the available cations may not be enough to turn biopolymer into the gel form [181]. Sodium alginate also has significant efficiency in enhancing the unsoaked CBR of dune sand [66]. A very low amount of xanthan $(0.4 \%)$ reduced $36 \%$ of the required thickness for the unstabilized sand.

Resilient modulus (RM) also increased when lignin, up to $12 \%$ (optimal content), was added in silt which was in line with the UCS results [58,182]. This coincidence was the same for adding protein-based biopolymers including casein and sodium caseinate into the dune sand [82]. Thus, it can be seen that the variation of pavement parameters (RM and CBR) for biopolymer-treated soil is in line with the UCS results. The criteria of pavement design consider a minimum amount for maximum compressive strength obtained from the UCS test; this standard value is determined based on specific conditions in different countries. The feasibility of using xanthan gum for sub-base stabilization as well as road shoulder construction has been investigated and compared with cement and geopolymers. The presented results showed that the UCS of xanthan-treated silty sand passed all design criteria in terms of the required UCS. Also, the higher ductility of xanthan-treated soil had a positive impact compared to cement and fly ash [122].

\subsection{Increasing Soil Bearing Capacity for Shallow Foundations}

Shallow foundations are designed based on an allowable bearing capacity that must meet the safety factor for the prevention of shear failure.. When the applied load exceeds the soil bearing capacity, the footing penetrates the soil either in horizontal or vertical directions so that it could lead to a bearing capacity failure. Soil bearing capacity is variable for different soil conditions and is dependent on several factors [198]. A number of works have already been studied the shear parameters of biopolymer treated soils especially for cohesion increment. A good result is expected in the case of biopolymers as soil binders. In a numerical model by PLAXIS 2D, it was shown that low amounts of guar and xanthan increased the soil bearing capacity, attenuated the negative effect of saturation degree, and decreased the settlement during and after saturation [174].

\subsection{Landfills}

One of the most common methods of waste disposal and management is landfill. The surface system of a landfill needs to be sufficiently resistant against wind and water erosion, promote vegetation if present by storing water, and satisfy aesthetic and ecological criteria. The cover system prevents the underlying layers from exposure to damaging environments, such as freeze-thaw, desiccation, and ultraviolet light. Landfills comprise a very lowpermeable barrier system to delay the contamination of leachate and toxic components into the soil and groundwater system. The permeability of liners in a landfill system should not exceed $10^{-7} \mathrm{~cm} / \mathrm{s}$, and the thickness must be more than $600 \mathrm{~mm}$ [199]. Clay liners with low hydraulic conductivity are used in landfill systems, but their drawbacks, mostly because of high volume change and cracking as well as non-renewability, limit their use [200]. Stabilizing the host soil with environment-friendly binders can be considered as an alternative to clay liners.

Biopolymer treated soils considerably improved the erodibility resistance by maintaining the soil ability of vegetation growth. Also, absorbing water due to the hydrophilicity of biopolymers enables the cover system to store water. The ability of vegetation promotion growth for biopolymer treated soil was investigated in a large-scale study for a one year period; biopolymer increased the vegetation density and higher sprouts were observed compared to the untreated soil [43]. Around $2.72 \times 10^{5}$ times decrease in hydraulic conductivity was recorded when guar gum was added to the soil, while the shear strength was also increased by more than $70 \%$. Furthermore, durability indexes under wet-dry cycles were placed in the permissible range. It is also notable that biopolymer treated soil is 
capable of enhancing the heavy metal attenuation capacity of the soil, causing less harmful leachate containing heavy metal to pass through the soil to groundwater [143]. Therefore, with the great potential of biopolymer-treated soil in landfill application, further use of biopolymers in research and practical applications is expected in the future.

\subsection{Biopolymers in Slurry Barrier Trench Excavations}

Bentonite slurry is used to stabilize the sides for trench excavation, which is called the slurry trench method of excavation. This technique enables excavation where a high groundwater profile exists, and the trench needs to be extended below the water level [201]. During the excavation process, the slurry is pumped into the trench to prevent the sides from collapse by applying hydrostatic pressure towards the walls, penetrating inside the pores, and forming a filter layer over the side surface. Usually, bentonite is the main material in this technique, but recently biopolymer slurry has shown a potential to be utilized as an alternative. The high gel strength of the biopolymer and low tendency to lose water make it capable of being used in this technique [202]. To stop internal erosion in an embankment dam, a biopolymer slurry trench can be excavated with partial penetration to reduce seepage occurring on the downstream slope in case the excavation should be continued beneath the water level. In 1997, guar gum slurry was utilized to stabilize sidewalls during the excavation process of installing a permeable iron barrier at Oak Ridge, Tennessee, USA. The biopolymer slurry trench method has also been used in several other projects in different parts of the world [203].

\section{Prospects and Limitations of Biopolymer in Soil Treatment}

It can be said that the most important reason for introducing biopolymers in soil strengthening is to mitigate the harmful effects of other environmentally unfriendly materials. Biopolymers would provide the opportunity of using sustainable materials with low impact on the environment as well as groundwater. Moreover, it has been shown that a smaller content of biopolymers would be able to obtain the same or higher strength compared with cement. Unlike some other soil improvement methods, the presence of fine soil is not considered an obstacle to using biopolymers, while using the MICP technique is also limited to coarse-grained soils, to reach a uniform distribution of precipitated calcite. Introducing biopolymer into the soil can be performed through various methods such as grouting, injection, mixing, and spraying $[9,15,204]$. In comparison to the MICP method, less time and complexity are needed in terms of the application and productivity of using biopolymers. In addition, biopolymers have the potential of mass production as well as relatively immediate reaction with soil particles, which enable them to be employed in temporary and rapid applications [15]. Furthermore, artificial intelligence methods and algorithms could be readily developed and deployed to optimize the performance of biopolymers as a viable soil improvement method. For example, genetic programming neural networks or Bayesian network have been successfully used in the study of geopolymer concrete and brick, which could be emulated for biopolymers $[205,206]$.

More research needs to be performed to resolve some limitations of biopolymer usage. The characteristics of biopolymer-treated soil can change under real environmental conditions such as $\mathrm{pH}$, temperature, wet-dry cycles, as well as ultraviolet radiation [207]. Additionally, the durability of biopolymer mixed with soil should be more comprehensively investigated, especially for degradation because of microorganisms. The types of microorganisms can differ completely from one soil to another, which means that each soil might need to be specifically evaluated in terms of biodegradability and duration. Also, a biopolymer-soil mixture may work well at a certain time of the year, while it has poor workability in a different season or atmospheric condition. Biopolymer-treated soil performance under saturated conditions should be studied further, as most biopolymers are quite sensitive to water.

Few studies have been performed to evaluate the effect of biopolymers in field conditions. Recently, a biopolymer was used to control the soil erosion in the field. Xanthan, 
casein, and xanthan-starch compound were utilized. Monitoring was carried out after 100 days to evaluate the vegetation density and shear strength. Biopolymer-treated soils exhibited an increase in shear strength compared to the untreated soil. In addition, the vegetation density increased considerably due to the addition of biopolymers [43]. The feasibility of utilizing biopolymers for pavement stabilization was studied in the treatment of a $50 \mathrm{~m}$-long pedestrian trail. The effectiveness was observed in enhanced surface stiffness and erosion resistance [43].

In terms of economic feasibility, using biopolymers in geotechnical applications is currently less feasible in comparison to traditional materials. The trend towards more commercialization during the last few decades has led to the cost reduction of some biopolymers, such as xanthan gum, the price of which has decreased from 30,000 US\$/ton to 3000 US\$/ton over 20 years [150]. Furthermore, the existing prices are usually for the high-quality grade of biopolymers, which are mostly used in food and medical applications. In recent years, lower-grade biopolymers have been successfully used in soil improvement work [18]. Successful identification of new products or bacteria strains [208] would enhance productivity as well as applying a wider use of technological tools [209] incorporating soil improvement methods [210] and would thus provide another major step towards mass application on real-life projects [211-215].

\section{Conclusions}

Adding biopolymer to act as a binder into the host soils is one of the most effective applications for soil treatment. In this study, a technical review has been conducted on the role of biopolymers in soil improvement and how they change the geotechnical properties of soils.

- Biopolymers from various sources have been employed. The most common source is biopolymers produced from plants. Animal-based and microorganism-based biopolymers have demonstrated great potential for geotechnical purposes. The ocean is also a valuable resource for extracting biopolymers from marine plants and animals.

- Sand particles are neutral in charge, such that the biopolymer adhesion mechanism is achieved via coating the soil particles and forming bridges amongst the particles. On the other hand, clay sheets tend to directly interact with biopolymer particles through different electrostatic interactions such as hydrogen bonding, ionic bonds, as well as van der Waals bonds. This behavior is due to the existence of negative charges and cations in clay minerals.

Important points of the geotechnical characteristics of biopolymer-treated soils are as follows:

- The unconfined compressive test is usually considered the most common test method to evaluate the behavior of biopolymer-treated soils. The general conclusion is that biopolymers increase the UCS values; however, the UCS improvement could be variable depending on the biopolymer and the soil testing conditions. Xanthan-treated sand achieved a compressive strength that was comparable to cement.

- The reported results of direct shear tests have also shown improvements in shear strengths, in particular on increasing the cohesion. Internal friction amongst soil particles experiences relatively lower strength improvement during treatment.

- $\quad$ By adding biopolymers, stiffer soil surfaces with improved strength could be achieved to resist wind and water erosion. Using biopolymers to control wind erosion is an effective short-term technique that could be resistant for at least one or two weeks.

- The physical soil properties have also been affected by adding biopolymer such that higher additive content led to higher liquid and plastic limits. However, this trend for the plasticity index (PI) was not the same, and both decreasing and increasing trends were observed, respectively.

- Variation of both the optimal moisture contents and maximum dry densities could vary due to various biopolymer and soil types. As many of the biopolymers employed for soil improvement are soluble in water, the moisture content is an important 
parameter for further research so that the improved soils achieve the desirable compaction conditions.

- The lack of research can be observed in the role of biopolymers used in pavement applications. However, the effective performance of biopolymers in increasing the CBR strength, resilient modulus (RM), and UCS has been reported. However, further research is still needed to assess its long-term cyclic durability under traffic or seismic loadings.

Various factors can affect the biotreated soil behavior. The most important factors are presented below:

- One advantage of using a biopolymer as a binder is the relatively low content needed to achieve a compressive strength that is comparable to traditional materials such as cement and lime. For some biopolymers, it can be seen that an optimal amount must be ascertained otherwise reduction in soil strength may be expected. Compared with other biopolymers, greater lignin content is needed to reach the optimal content.

- Sensitivity to water is considered to be a fundamental issue of biopolymers in soil treatment; strength loss and apparent swelling/shrinkage behavior are the drawbacks. The maximum strength of biopolymer-treated soil is obtained in the dry state and higher moisture content will lead to lower strength. Susceptibility to water is also different from one biopolymer to another.

- The durability of the biopolymer-treated soil requires more attention because various environmental conditions including wetting-drying cycles, freeze-thaw cycles, microorganisms, and ultraviolet radiation could significantly decrease the strength. For gellan gum, exposure to wet-dry cycles resulted in major damage to the biopolymer matrix and thus loss of strength. However, xanthan gum offered a relatively better efficiency under wet-dry cycles.

- Biopolymer-treated soil properties could change significantly under different thermal variations. Thermogelatin biopolymers, such as agar and gellan gums, are among the biopolymers most susceptible to temperature. Some biopolymers (casein, alginate, and beta-glucan) perform better at their optimal temperatures. Generally, high temperatures may lead to the decomposition of the biopolymers.

- The moisture content of the biopolymer soil mixture has a close relationship with dehydration time, in such a way that time causes the biotreated sample to lose its moisture and form the linked network. If the samples are under cured in normal atmospheric conditions, it takes time for the specimens to achieve more than $90 \%$ of their maximum strength value, which could be considered as the optimal dehydration time. This optimal value could vary from 3 to 28 days, depending on soil and biopolymer types.

- The brittle behavior of biopolymer-treated soils could be modified by adding fiber into the mixture to increase their flexibility. Along with synthetic products, natural fibers such as date palm fibers and animal wools have demonstrated a positive impact on the biotreated soil's characteristics.

Author Contributions: Conceptualization, H.F., D.E.L.O., J.Y. and I.C.; investigation, H.F., D.E.L.O., J.Y. and I.C.; writing - original draft preparation, H.F.; writing-review and editing, D.E.L.O., J.Y. and I.C.; supervision, D.E.L.O., J.Y. and I.C. All authors have read and agreed to the published version of the manuscript.

Funding: This research received no external funding.

Conflicts of Interest: The authors declare no conflict of interest.

\section{References}

1. Nicholson, P.G. Soil Improvement and Ground Modification Methods; Butterworth-Heinemann: Oxford, UK, 2014.

2. Leong, H.Y.; Ong, D.E.L.; Sanjayan, J.G.; Nazari, A. Strength development of soil-fly ash geopolymer: Assessment of soil, fly ash, alkali activators, and water. J. Mater. Civ. Eng. 2018, 30, 04018171. [CrossRef] 
3. Saberian, M.; Li, J.; Boroujeni, M.; Law, D.; Li, C.-Q. Application of demolition wastes mixed with crushed glass and crumb rubber in pavement base/subbase. Resour. Conserv. Recycl. 2020, 156, 104722. [CrossRef]

4. Saberian Boroujeni, M.; Li, J.; Nguyen, B.; Saberian Boroujeni, M. Experimental and analytical study of dynamic properties of UGM materials containing waste rubber. Soil Dyn. Earthq. Eng. 2019, 130, 1-12. [CrossRef]

5. Correia, A.G.; Winter, M.; Puppala, A. A review of sustainable approaches in transport infrastructure geotechnics. Transp. Geotech. 2016, 7, 21-28. [CrossRef]

6. Cola, S.; Schenato, L.; Brezzi, L.; Tchamaleu Pangop, F.C.; Palmieri, L.; Bisson, A. Composite anchors for slope stabilisation: Monitoring of their in-situ behaviour with optical fibre. Geosciences 2019, 9, 240. [CrossRef]

7. Toghroli, A.; Mehrabi, P.; Shariati, M.; Trung, N.T.; Jahandari, S.; Rasekh, H. Evaluating the use of recycled concrete aggregate and pozzolanic additives in fiber-reinforced pervious concrete with industrial and recycled fibers. Constr. Build. Mater. 2020, 252, 118997. [CrossRef]

8. Jahandari, S.; Saberian, M.; Tao, Z.; Mojtahedi, S.F.; Li, J.; Ghasemi, M.; Rezvani, S.S.; Li, W. Effects of saturation degrees, freezing-thawing, and curing on geotechnical properties of lime and lime-cement concretes. Cold Reg. Sci. Technol. 2019, 160, 242-251. [CrossRef]

9. Chang, I.; Lee, M.; Cho, G.-C. Global $\mathrm{CO}_{2}$ Emission-Related Geotechnical Engineering Hazards and the Mission for Sustainable Geotechnical Engineering. Energies 2019, 12, 2567. [CrossRef]

10. Etim, R.; Eberemu, A.; Osinubi, K. Stabilization of black cotton soil with lime and iron ore tailings admixture. Transp. Geotech. 2017, 10, 85-95. [CrossRef]

11. Rahgozar, M.A.; Saberian, M.; Li, J. Soil stabilization with non-conventional eco-friendly agricultural waste materials: An experimental study. Transp. Geotech. 2018, 14, 52-60. [CrossRef]

12. Afshar, A.; Jahandari, S.; Rasekh, H.; Shariati, M.; Afshar, A.; Shokrgozar, A. Corrosion resistance evaluation of rebars with various primers and coatings in concrete modified with different additives. Constr. Build. Mater. 2020, 262, 120034. [CrossRef]

13. Bauer, V. Global Cement Production, Responsible for $8 \%$ of the World's $\mathrm{CO}_{2}$ Emissions. Available online: https: / /www.timberonline.net/uebrige_wirtschaft/2018/12/global-cement-production.html (accessed on 31 May 2021).

14. Wang, T. Cement Production Globally and in the U.S. from 2010 to 2018. Available online: https: / www.statista.com/statistics / 219343/cement-production-worldwide/ (accessed on 31 May 2021).

15. Chang, I.; Im, J.; Cho, G.-C. Introduction of microbial biopolymers in soil treatment for future environmentally-friendly and sustainable geotechnical engineering. Sustainability 2016, 8, 251. [CrossRef]

16. Ong, D.E.L.; Choo, C. Sustainable construction of a bored pile foundation system in erratic phyllite. In Proceedings of the ASEAN Australian Engineering Congress, Kuching, Malaysia, 25-27 July 2011.

17. Ngu, L.H.; Song, J.W.; Hashim, S.S.; Ong, D.E.L. Lab-scale atmospheric $\mathrm{CO}_{2}$ absorption for calcium carbonate precipitation in sand. Greenh. Gases Sci. Technol. 2019, 9, 519-528. [CrossRef]

18. Omoregie, A.I.; Ngu, L.H.; Ong, D.E.L.; Nissom, P.M. Low-cost cultivation of Sporosarcina pasteurii strain in food-grade yeast extract medium for microbially induced carbonate precipitation (MICP) application. Biocatal. Agric. Biotechnol. 2019, 17, 247-255. [CrossRef]

19. Liu, S.; Wang, R.; Yu, J.; Peng, X.; Cai, Y.; Tu, B. Effectiveness of the anti-erosion of an MICP coating on the surfaces of ancient clay roof tiles. Constr. Build. Mater. 2020, 243, 118202. [CrossRef]

20. Ghasemzadeh, H.; Mehrpajouh, A.; Pishvaei, M. Laboratory analyses of Kaolinite stabilized by vinyl polymers with different monomer types. Eng. Geol. 2021, 280, 105938. [CrossRef]

21. DeJong, J.; Soga, K.; Kavazanjian, E.; Burns, S.; Van Paassen, L.; Al Qabany, A.; Aydilek, A.; Bang, S.; Burbank, M.; Caslake, L.F. Biogeochemical processes and geotechnical applications: Progress, opportunities and challenges. Geotechnique 2013, 63, 287-301. [CrossRef]

22. Omoregie, A.I.; Palombo, E.A.; Ong, D.E.L.; Nissom, P.M. Biocementation of sand by Sporosarcina pasteurii strain and technicalgrade cementation reagents through surface percolation treatment method. Constr. Build. Mater. 2019, 228, 116828. [CrossRef]

23. Omoregie, A.I.; Palombo, E.A.; Ong, D.E.L.; Nissom, P.M. A feasible scale-up production of Sporosarcina pasteurii using custom-built stirred tank reactor for in-situ soil biocementation. Biocatal. Agric. Biotechnol. 2020, 24, 101544. [CrossRef]

24. Bahmani, M.; Fatehi, H.; Noorzad, A.; Hamedi, J. Biological soil improvement using new environmental bacteria isolated from northern Iran. Environ. Geotech. 2019, 40, 1-13. [CrossRef]

25. Mujah, D.; Shahin, M.A.; Cheng, L. State-of-the-art review of biocementation by microbially induced calcite precipitation (MICP) for soil stabilization. Geomicrobiol. J. 2017, 34, 524-537. [CrossRef]

26. Choi, S.-G.; Chang, I.; Lee, M.; Lee, J.-H.; Han, J.-T.; Kwon, T.-H. Review on geotechnical engineering properties of sands treated by microbially induced calcium carbonate precipitation (MICP) and biopolymers. Constr. Build. Mater. 2020, $246,118415$. [CrossRef]

27. Tang, C.-S.; Yin, L.-y.; Jiang, N.-J.; Zhu, C.; Zeng, H.; Li, H.; Shi, B. Factors affecting the performance of microbial-induced carbonate precipitation (MICP) treated soil: A review. Environ. Earth Sci. 2020, 79, 1-23. [CrossRef]

28. Dhami, N.K.; Reddy, M.S.; Mukherjee, A. Significant indicators for biomineralisation in sand of varying grain sizes. Constr. Build. Mater. 2016, 104, 198-207. [CrossRef]

29. Sharma, M.; Satyam, N.; Reddy, K.R. Effect of freeze-thaw cycles on engineering properties of biocemented sand under different treatment conditions. Eng. Geol. 2021, 284, 106022. [CrossRef] 
30. Achal, V.; Mukherjee, A. A review of microbial precipitation for sustainable construction. Constr. Build. Mater. 2015, 93, 1224-1235. [CrossRef]

31. Chu, J.; Ivanov, V.; Stabnikov, V.; Li, B. Microbial method for construction of an aquaculture pond in sand. Géotechnique 2013, 63, 871-875. [CrossRef]

32. Kwon, T.-H.; Ajo-Franklin, J.B. High-frequency seismic response during permeability reduction due to biopolymer clogging in unconsolidated porous media. Geophysics 2013, 78, EN117-EN127. [CrossRef]

33. Noh, D.H.; Ajo-Franklin, J.B.; Kwon, T.H.; Muhunthan, B. P and S wave responses of bacterial biopolymer formation in unconsolidated porous media. J. Geophys. Res. Biogeosci. 2016, 121, 1158-1177. [CrossRef]

34. Ham, S.-M.; Chang, I.; Noh, D.-H.; Kwon, T.-H.; Muhunthan, B. Improvement of Surface Erosion Resistance of Sand by Microbial Biopolymer Formation. J. Geotech. Geoenviron. Eng. 2018, 144, 06018004. [CrossRef]

35. Baveye, P.; Vandevivere, P.; Hoyle, B.L.; DeLeo, P.C.; de Lozada, D.S. Environmental impact and mechanisms of the biological clogging of saturated soils and aquifer materials. Crit. Rev. Environ. Sci. Technol. 1998, 28, 123-191. [CrossRef]

36. Dunsmore, B.C.; Bass, C.J.; Lappin-Scott, H.M. A novel approach to investigate biofilm accumulation and bacterial transport in porous matrices. Environ. Microbiol. 2004, 6, 183-187. [CrossRef]

37. Matsubara, H. Stabilisation of weathered limestone surfaces using microbially enhanced calcium carbonate deposition. Eng. Geol. 2021, 284, 106044. [CrossRef]

38. Abdullah, H.H.; Shahin, M.A.; Walske, M.L. Review of fly-ash-based geopolymers for soil stabilisation with special reference to clay. Geosciences 2020, 10, 249. [CrossRef]

39. Sadeghian, F.; Haddad, A.; Jahandari, S.; Rasekh, H.; Ozbakkaloglu, T. Effects of electrokinetic phenomena on the load-bearing capacity of different steel and concrete piles: A small-scale experimental study. Can. Geotech. J. 2021, 58, 741-746. [CrossRef]

40. Rebata-Landa, V.; Santamarina, J.C. Mechanical effects of biogenic nitrogen gas bubbles in soils. J. Geotech. Geoenviron. Eng. 2012, 138, 128-137. [CrossRef]

41. He, J.; Chu, J.; Ivanov, V. Mitigation of liquefaction of saturated sand using biogas. Geotechnique 2013, 63, 267-275. [CrossRef]

42. Stal, L.J. Biopolymer. In Encyclopedia of Astrobiology; Gargaud, M., Amils, R., Quintanilla, J.C., Cleaves, H.J., Irvine, W.M., Pinti, D.L., Viso, M., Eds.; Springer: Berlin/Heidelberg, Germany, 2011; pp. 199-200.

43. Chang, I.; Lee, M.; Tran, A.T.P.; Lee, S.; Kwon, Y.-M.; Im, J.; Cho, G.-C. Review on biopolymer-based soil treatment (BPST) technology in geotechnical engineering practices. Transp. Geotech. 2020, 24, 100385. [CrossRef]

44. Liu, X.; Wang, C.; Wang, A.; Qu, J.; Wen, Y.; Wei, B. Application of Cellulose and Cellulose Nanofibers in Oil Exploration. Pap. Biomater. 2019, 4, 69.

45. Mays, G.C.; Hutchinson, A.R. Adhesives in Civil Engineering; Cambridge University Press: Cambridge, UK, 2005.

46. Zhang, Y.; Zhao, Q.; Liu, C.; Zhou, M. Properties comparison of mortars with welan gum or cellulose ether. Constr. Build. Mater. 2016, 102, 648-653. [CrossRef]

47. Plank, J. Applications of biopolymers in construction engineering. Biopolym. Online Biol. Chem. Biotechnol. Appl. 2005, 10. [CrossRef]

48. Khatami, H.; O’Kelly, B.C. Prevention of bleeding of particulate grouts using biopolymers. Constr. Build. Mater. 2018, 192, 202-209. [CrossRef]

49. Li, M.; Xie, D.; Shu, Q.; Ou, H.; Guo, X. Study on sodium fatty alcohol polyoxyethyleneether sulfate relieve the contamination of oil well cement with mineral oil-based drilling fluids. Constr. Build. Mater. 2018, 163, 450-459. [CrossRef]

50. Rempel, A.W.; Rempel, A.R. Frost resilience of stabilized earth building materials. Geosciences 2019, 9, 328. [CrossRef]

51. Niaounakis, M. Biopolymers: Applications and Trends; William Andrew: Norwich, NY, USA, 2015.

52. Gupta, S.C.; Hooda, K.; Mathur, N.; Gupta, S. Tailoring of guar gum for desert sand stabilization. Indian J. Chem. Technol. 2009, 16, 507-512.

53. Chudzikowski, R. Guar gum and its applications. J. Soc. Cosmet. Chem. 1971, 22, 43.

54. Chen, R.; Zhang, L.; Budhu, M. Biopolymer stabilization of mine tailings. J. Geotech. Geoenviron. Eng. 2013, 139, 1802-1807. [CrossRef]

55. Martone, P.T.; Estevez, J.M.; Lu, F.; Ruel, K.; Denny, M.W.; Somerville, C.; Ralph, J. Discovery of lignin in seaweed reveals convergent evolution of cell-wall architecture. Curr. Biol. 2009, 19, 169-175. [CrossRef]

56. Hemmilä, V.; Trischler, J.; Sandberg, D. Lignin: An adhesive raw material of the future or waste of research energy? In Proceedings of the Northern European Network for Wood Science and Engineering (WSE. Proceedings of the 9th Meeting), Hannover, Germany, 11-12 September 2013; pp. 98-103.

57. Ta'negonbadi, B.; Noorzad, R. Stabilization of clayey soil using lignosulfonate. Transp. Geotech. 2017, 12, 45-55. [CrossRef]

58. Zhang, T.; Liu, S.; Cai, G.; Puppala, A.J. Experimental investigation of thermal and mechanical properties of lignin treated silt. Eng. Geol. 2015, 196, 1-11. [CrossRef]

59. Ivanov, V.; Chu, J. Applications of microorganisms to geotechnical engineering for bioclogging and biocementation of soil in situ. Rev. Environ. Sci. Biol. Technol. 2008, 7, 139-153. [CrossRef]

60. McHugh, D.J. A Guide to the Seaweed Industry; Food and Agriculture Organization of the United Nations: Rome, Italy, 2003.

61. Hernandez-Carmona, G.; Freile-Pelegrín, Y.; Hernández-Garibay, E. Conventional and alternative technologies for the extraction of algal polysaccharides. In Functional Ingredients from Algae for Foods and Nutraceuticals; Elsevier: Amsterdam, The Netherlands, 2013; pp. 475-516. 
62. Chang, I.; Prasidhi, A.K.; Im, J.; Cho, G.-C. Soil strengthening using thermo-gelation biopolymers. Constr. Build. Mater. 2015, 77, 430-438. [CrossRef]

63. Bacic, A.; Fincher, G.B.; Stone, B.A. Chemistry, Biochemistry, and Biology of 1-3 Beta Glucans and Related Polysaccharides; Academic Press: Cambridge, MA, USA, 2009.

64. Ouwerx, C.; Velings, N.; Mestdagh, M.; Axelos, M. Physico-chemical properties and rheology of alginate gel beads formed with various divalent cations. Polym. Gels. Netw. 1998, 6, 393-408. [CrossRef]

65. Lee, K.Y.; Mooney, D.J. Alginate: Properties and biomedical applications. Prog. Polym. Sci. 2012, 37, 106-126. [CrossRef]

66. Fatehi, H.; Bahmani, M.; Noorzad, A. Strengthening of Dune Sand with Sodium Alginate Biopolymer. In Proceedings of the Geo-Congress 2019: Soil Improvement, Philadelphia, Pennsylvania, 24-27 March 2019; pp. 157-166.

67. Kulkarni, V.S.; Shaw, C. Essential Chemistry for Formulators of Semisolid and Liquid Dosages; Elsevier Science: Amsterdam, The Netherlands, 2015.

68. Milas, M.; Rinaudo, M. Properties of xanthan gum in aqueous solutions: Role of the conformational transition. Carbohydr. Res. 1986, 158, 191-204. [CrossRef]

69. Chen, C.S.H.; Sheppard, E. Conformation and shear stability of xanthan gum in solution. Polym. Eng. Sci. 1980, 20, 512-516. [CrossRef]

70. Garcia-Ochoa, F.; Santos, V.; Casas, J.; Gómez, E. Xanthan gum: Production, recovery, and properties. Biotechnol. Adv. 2000, 18, 549-579. [CrossRef]

71. Jansson, P.-E.; Lindberg, B.; Sandford, P.A. Structural studies of gellan gum, an extracellular polysaccharide elaborated by Pseudomonas elodea. Carbohydr. Res. 1983, 124, 135-139. [CrossRef]

72. Chang, I.; Jeon, M.; Cho, G.-C. Application of microbial biopolymers as an alternative construction binder for earth buildings in underdeveloped countries. Int. J. Polym. Sci. 2015, 2015, 326745. [CrossRef]

73. Kwon1a, Y.-M.; Im1b, J.; Chang, I.; Cho, G.-C. e-polylysine biopolymer for coagulation of clay suspensions. Geomech. Eng. 2017. [CrossRef]

74. Shima, S.; MATSUOKA, H.; IWAMOTO, T.; SAKAI, H. Antimicrobial action of $\varepsilon$-poly-L-lysine. J. Antibiot. 1984, $37,1449-1455$. [CrossRef]

75. Hemmings, H.C.; Egan, T.D. Pharmacology and Physiology for Anesthesia: Foundations and Clinical Application: Expert Consult-Online and Print; Elsevier/Saunders: Amsterdam, The Netherlands, 2013.

76. Lee, D.W.; Lim, C.; Israelachvili, J.N.; Hwang, D.S. Strong adhesion and cohesion of chitosan in aqueous solutions. Langmuir 2013, 29, 14222-14229. [CrossRef]

77. Kumar, M.N.R. A review of chitin and chitosan applications. React. Funct. Polym. 2000, 46, 1-27. [CrossRef]

78. Jayasuriya, A. Production of micro-and nanoscale chitosan particles for biomedical applications. In Chitosan Based Biomaterials Volume 1; Elsevier: Amsterdam, The Netherlands, 2017; pp. 185-209.

79. Wilson, M.; Wilson, L. Clay mineralogy and shale instability: An alternative conceptual analysis. Clay Miner. 2014, 49, 127-145. [CrossRef]

80. Hataf, N.; Ghadir, P.; Ranjbar, N. Investigation of soil stabilization using chitosan biopolymer. J. Clean. Prod. 2018, 170, 1493-1500. [CrossRef]

81. Southward, C. Manufacture and applications and edible casein products. I. Manufacture and properties. N. Z. J. Dairy Sci. Technol. 1985, 20, 79-101.

82. Fatehi, H.; Abtahi, S.M.; Hashemolhosseini, H.; Hejazi, S.M. A novel study on using protein based biopolymers in soil strengthening. Constr. Build. Mater. 2018, 167, 813-821. [CrossRef]

83. Némethy, G.; Scheraga, H.A. Structure of water and hydrophobic bonding in proteins. I. A model for the thermodynamic properties of liquid water. J. Chem. Phys. 1962, 36, 3382-3400. [CrossRef]

84. La Rosa, A. Life cycle assessment of biopolymers. In Biopolymers and Biotech Admixtures for Eco-Efficient Construction Materials; Elsevier: Amsterdam, The Netherlands, 2016; pp. 57-78.

85. Girod, B.; van Vuuren, D.P.; de Vries, B. Influence of travel behavior on global $\mathrm{CO}_{2}$ emissions. Transp. Res. Part A Policy Pract. 2013, 50, 183-197. [CrossRef]

86. Zhang, R.; Long, M.; Zheng, J. Comparison of environmental impacts of two alternative stabilization techniques on expansive soil slopes. Adv. Civ. Eng. 2019, 2019, 9454929. [CrossRef]

87. Celauro, C.; Corriere, F.; Guerrieri, M.; Casto, B.L. Environmentally appraising different pavement and construction scenarios: A comparative analysis for a typical local road. Transp. Res. Part D Transp. Environ. 2015, 34, 41-51. [CrossRef]

88. Marcelino-Sadaba, S.; Kinuthia, J.; Oti, J.; Meneses, A.S. Challenges in Life Cycle Assessment (LCA) of stabilised clay-based construction materials. Appl. Clay Sci. 2017, 144, 121-130. [CrossRef]

89. Uwasu, M.; Hara, K.; Yabar, H. World cement production and environmental implications. Environ. Dev. 2014, 10, 36-47. [CrossRef]

90. da Rocha, C.G.; Passuello, A.; Consoli, N.C.; Samaniego, R.A.Q.; Kanazawa, N.M. Life cycle assessment for soil stabilization dosages: A study for the Paraguayan Chaco. J. Clean. Prod. 2016, 139, 309-318. [CrossRef]

91. Saberian, M.; Jahandari, S.; Li, J.; Zivari, F. Effect of curing, capillary action, and groundwater level increment on geotechnical properties of lime concrete: Experimental and prediction studies. J. Rock Mech. Geotech. Eng. 2017, 9, 638-647. [CrossRef] 
92. Kabir, E.; Kaur, R.; Lee, J.; Kim, K.-H.; Kwon, E.E. Prospects of biopolymer technology as an alternative option for non-degradable plastics and sustainable management of plastic wastes. J. Clean. Prod. 2020, 258, 120536. [CrossRef]

93. Stoica, M.; Antohi, V.M.; Zlati, M.L.; Stoica, D. The financial impact of replacing plastic packaging by biodegradable biopolymers-A smart solution for the food industry. J. Clean. Prod. 2020, 277, 124013. [CrossRef]

94. Detzel, A.; Kauertz, B.; Derreza-Greeven, C.; Kirsch, A. Untersuchung der Umweltwirkungen von Verpackungen aus biologisch abbaubaren Kunststoffen; Umweltbundesamt: Dessau-Roßlau, Germany, 2012.

95. Song, J.; Murphy, R.; Narayan, R.; Davies, G. Biodegradable and compostable alternatives to conventional plastics. Philos. Trans. R. Soc. B Biol. Sci. 2009, 364, 2127-2139. [CrossRef]

96. Scown, C.D.; Gokhale, A.A.; Willems, P.A.; Horvath, A.; McKone, T.E. Role of lignin in reducing life-cycle carbon emissions, water use, and cost for United States cellulosic biofuels. Environ. Sci. Technol. 2014, 48, 8446-8455. [CrossRef]

97. Healable. Is Xanthan Gum Good or Bad? Available online: https://healabel.com/x-ingredients/xanthan-gum (accessed on 31 May 2021).

98. Healable. Is Agar Agar Good or Bad? Available online: https:/ /healabel.com/a-ingredients/agar-agar (accessed on 31 May 2021).

99. Gresta, F.; De Luca, A.I.; Strano, A.; Falcone, G.; Santonoceto, C.; Anastasi, U.; Gulisano, G. Economic and environmental sustainability analysis of guar (Cyamopsis tetragonoloba L.) farming process in a Mediterranean area: Two case studies. Ital. J. Agron. 2014, 9, 20-24. [CrossRef]

100. Heusala, H.; Sinkko, T.; Sözer, N.; Hytönen, E.; Mogensen, L.; Knudsen, M.T. Carbon footprint and land use of oat and faba bean protein concentrates using a life cycle assessment approach. J. Clean. Prod. 2020, 242, 118376. [CrossRef]

101. Allwood, J.W.; Martinez-Martin, P.; Xu, Y.; Cowan, A.; Pont, S.; Griffiths, I.; Sungurtas, J.; Clarke, S.; Goodacre, R.; Marshall, A.; et al. Assessing the impact of nitrogen supplementation in oats across multiple growth locations and years with targeted phenotyping and high-resolution metabolite profiling approaches. Food Chem. 2021, 355, 129585. [CrossRef]

102. Healable. Are Oats Good or Bad? Available online: https:/ / healabel.com/o-ingredients/oats (accessed on 31 May 2020 ).

103. Langlois, J.; Fréon, P.; Delgenès, J.-P.; Steyer, J.-P.; Helias, A. Life cycle assessment of alginate production. In Proceedings of the 8th International Conference on LCA in the Agri-Food Sector, Saint-Malo, France, 2 October 2012.

104. Muñoz, I.; Rodríguez, C.; Gillet, D.; Moerschbacher, B.M. Life cycle assessment of chitosan production in India and Europe. Int. J. Life Cycle Assess. 2018, 23, 1151-1160. [CrossRef]

105. Gerber, P.; Vellinga, T.; Opio, C.; Henderson, B.; Steinfeld, H. Greenhouse Gas Emissions from the Dairy Sector: A Life Cycle As-sessment; Food and Agricultural Organisation of the United Nations: Rome, Italy, 2010.

106. Flysjö, A.M. Greenhouse Gas Emissions in Milk and Dairy Product Chains: Improving the Carbon Footprint of Dairy Products. Available online: http:/ / pure.au.dk/portal/files/45485022/Anna_20Flusj_.pdf (accessed on 31 May 2021).

107. Chang, I.; Im, J.; Chung, M.-K.; Cho, G.-C. Bovine casein as a new soil strengthening binder from diary wastes. Constr. Build. Mater. 2018, 160, 1-9. [CrossRef]

108. Niaounakis, M. Biopolymers: Reuse, Recycling, and Disposal; William Andrew: Norwich, NY, USA, 2013.

109. Barton, C. Clay minerals. In Encyclopedia of Soil Science; Rattan Lal, ed. Marcel Dekker: New York, NY, USA, $2002 ;$ pp. 187-192.

110. Tombácz, E.; Szekeres, M. Surface charge heterogeneity of kaolinite in aqueous suspension in comparison with montmorillonite. Appl. Clay Sci. 2006, 34, 105-124. [CrossRef]

111. Latifi, N.; Horpibulsuk, S.; Meehan, C.L.; Abd Majid, M.Z.; Tahir, M.M.; Mohamad, E.T. Improvement of problematic soils with biopolymer-an environmentally friendly soil stabilizer. J. Mater. Civ. Eng. 2017, 29, 04016204. [CrossRef]

112. Strawn, D.G.; Bohn, H.L.; O'Connor, G.A. Soil Chemistry; John Wiley \& Sons: Hoboken, NJ, USA, 2019.

113. Chang, I.; Im, J.; Prasidhi, A.K.; Cho, G.-C. Effects of Xanthan gum biopolymer on soil strengthening. Constr. Build. Mater. 2015, 74, 65-72. [CrossRef]

114. Cabalar, A.F.; Awraheem, M.H.; Khalaf, M.M. Geotechnical properties of a low-plasticity clay with biopolymer. J. Mater. Civ. Eng. 2018, 30, 04018170. [CrossRef]

115. Chang, I.; Cho, G.-C. Strengthening of Korean residual soil with $\beta-1,3 / 1$, 6-glucan biopolymer. Constr. Build. Mater. 2012, 30, 30-35. [CrossRef]

116. Singh, S.P.; Das, R.; Seth, D. Plasticity and Strength Characteristics of Expansive Soil Treated with Xanthan Gum Biopolymer. In Problematic Soils and Geoenvironmental Concerns; Springer: Berlin/Heidelberg, Germany, 2021; pp. 649-663.

117. Soldo, A.; Miletić, M.; Auad, M.L. Biopolymers as a sustainable solution for the enhancement of soil mechanical properties. Sci. Rep. 2020, 10, 267. [CrossRef]

118. Singh, S.P.; Das, R. Geo-engineering properties of expansive soil treated with xanthan gum biopolymer. Geomech. Geoeng. 2019, 15, 107-112. [CrossRef]

119. Soldo, A.; Miletić, M. Study on Shear Strength of Xanthan Gum-Amended Soil. Sustainability 2019, 11, 6142. [CrossRef]

120. Toufigh, V.; Ghassemi, P. Control and Stabilization of Fugitive Dust: Using Eco-Friendly and Sustainable Materials. Int. J. Geomech. 2020, 20, 04020140. [CrossRef]

121. Chen, C.; Peng, Z.; Gu, J.; Peng, Y.; Huang, X.; Wu, L. Exploring Environmentally Friendly Biopolymer Material Effect on Soil Tensile and Compressive Behavior. Int. J. Environ. Res. Public Health 2020, 17, 9032. [CrossRef] [PubMed]

122. Lee, S.; Chung, M.; Park, H.M.; Song, K.-I.; Chang, I. Xanthan Gum Biopolymer as Soil-Stabilization Binder for Road Construction Using Local Soil in Sri Lanka. J. Mater. Civ. Eng. 2019, 31, 06019012. [CrossRef] 
123. Lee, M.; Im, J.; Cho, G.-C.; Ryu, H.H.; Chang, I. Interfacial Shearing Behavior along Xanthan Gum Biopolymer-Treated Sand and Solid Interfaces and Its Meaning in Geotechnical Engineering Aspects. Appl. Sci. 2021, 11, 139. [CrossRef]

124. Chen, C.; Wu, L.; Perdjon, M.; Huang, X.; Peng, Y. The drying effect on xanthan gum biopolymer treated sandy soil shear strength. Constr. Build. Mater. 2019, 197, 271-279. [CrossRef]

125. Bonal, N.; Prasad, A.; Verma, A. Use of biopolymers to enhance the geotechnical properties of coal mine overburden waste. Géotech. Lett. 2020, 10, 179-185. [CrossRef]

126. Kwon, Y.-M.; Ham, S.-M.; Kwon, T.-H.; Cho, G.-C.; Chang, I. Surface-erosion behaviour of biopolymer-treated soils assessed by EFA. Géotech. Lett. 2020, 10, 106-112. [CrossRef]

127. Lee, S.; Chung, M.; Kwon, Y.; Cho, G.; Chang, I. Investigation of erosion behavior of biopolymer treated soil using laboratory hydraulic flume testing. In Proceedings of the 16th Asian Regional Conference on Soil Mechanics and Geotechnical Engineering, Taipei, Taiwan, 14-18 October 2019.

128. Movasat, M.; Tomac, I. Post-Fire Mudflow Prevention by Biopolymer Treatment of Water Repellent Slopes. In Proceedings of the Geo-Congress, Minneapolis, MN, USA, 25-28 February 2020; pp. 170-178.

129. Elkafoury, A.; Azzam, W. Utilize Xanthan gum for enhancing CBR value of used cooking oil-contaminated fine sand subgrade soil for pavement structures. Innov. Infrastruct. Solut. 2021, 6, 1-10. [CrossRef]

130. Ghasemzadeh, H.; Modiri, F. Application of novel Persian gum hydrocolloid in soil stabilization. Carbohydr. Polym. 2020, 246, 116639. [CrossRef]

131. Ni, J.; Li, S.-S.; Ma, L.; Geng, X.-Y. Performance of soils enhanced with eco-friendly biopolymers in unconfined compression strength tests and fatigue loading tests. Constr. Build. Mater. 2020, 263, 120039. [CrossRef]

132. Rashid, A.S.A.; Tabatabaei, S.; Horpibulsuk, S.; Yunus, N.Z.M.; Hassan, W.H.W. Shear Strength Improvement of Lateritic Soil Stabilized by Biopolymer Based Stabilizer. Geotech. Geol. Eng. 2019, 37, 5533-5541. [CrossRef]

133. Joga, J.R.; Varaprasad, B. Sustainable Improvement of Expansive Clays Using Xanthan Gum as a Biopolymer. Civ. Eng. J. 2019, 5, 1893-1903. [CrossRef]

134. Kwon1a, Y.-M.; Chang2b, I.; Lee1c, M.; Cho, G.-C. Geotechnical engineering behavior of biopolymer-treated soft marine soil. Geomech. Eng. 2019, 17, 453-464.

135. Barani, O.R.; Barfar, P. Effect of Xanthan Gum Biopolymer on Fracture Properties of Clay. J. Mater. Civ. Eng. 2021, 33, 04020426. [CrossRef]

136. Biju, M.; Arnepalli, D. Effect of biopolymers on permeability of sand-bentonite mixtures. J. Rock Mech. Geotech. Eng. 2020, 12, 1093-1102. [CrossRef]

137. Chang, I.; Kwon, Y.-M.; Im, J.; Cho, G.-C. Soil consistency and interparticle characteristics of xanthan gum biopolymer-containing soils with pore-fluid variation. Can. Geotech. J. 2019, 56, 1206-1213. [CrossRef]

138. Sujatha, E.R.; Atchaya, S.; Sivasaran, A.; Keerdthe, R. Enhancing the geotechnical properties of soil using xanthan gum-an eco-friendly alternative to traditional stabilizers. Bull. Eng. Geol. Environ. 2021, 80, 1157-1167. [CrossRef]

139. Khosravi, M.; Tabarsa, A.; Osouli, A.; Latifi, N. A biopolymer-based waterproofing mortar for irrigation channel joints. In Proceedings of the Geo-Congress 2020, Minneapolis, MN, USA, 25-28 February 2020; pp. 159-169.

140. Joga, J.R.; Varaprasad, B. Effect of xanthan gum biopolymer on dispersive properties of soils. World J. Eng. 2020, $17,563-571$. [CrossRef]

141. Reddy, J.J.; Varaprasad, B.; Reddy, P.V. Application of Grey Taguchi Method to optimize the internal erosion parameters of stabilized soil. Multiscale Multidiscip. Model. Exp. Des. 2020, 4, 99-108. [CrossRef]

142. Sujatha, E.R.; Sivaraman, S.; Subramani, A.K. Impact of hydration and gelling properties of guar gum on the mechanism of soil modification. Arab. J. Geosci. 2020, 13, 1-12. [CrossRef]

143. Kumar, S.A.; Sujatha, E.R.; Pugazhendi, A.; Jamal, M.T. Guar gum-stabilized soil: A clean, sustainable and economic alternative liner material for landfills. Clean Technol. Environ. Policy 2021. [CrossRef]

144. Zhao, Y.; Zhuang, J.; Wang, Y.; Jia, Y.; Niu, P.; Jia, K. Improvement of loess characteristics using sodium alginate. Bull. Eng. Geol. Environ. 2019, 79, 1879-1891. [CrossRef]

145. Lemboye, K.; Almajed, A.; Alnuaim, A.; Arab, M.; Alshibli, K. Improving sand wind erosion resistance using renewable agriculturally derived biopolymers. Aeolian Res. 2021, 49, 100663. [CrossRef]

146. Singh, S.P.; Palsule, P.S.; Anand, G. Strength Properties of Expansive Soil Treated with Sodium Lignosulfonate. In Problematic Soils and Geoenvironmental Concerns; Springer: Berlin/Heidelberg, Germany, 2021; pp. 665-679.

147. Zhang, J.; Han, Y.; Wang, X.; Bian, H. Experimental Investigation of the Dynamic Characteristics of Treated Silt Using Lignin: Case Study of Yellow River Flood Basin. Int. J. Geomech. 2021, 21, 04021056. [CrossRef]

148. QABANY, A.A.; Soga, K. Effect of chemical treatment used in MICP on engineering properties of cemented soils. Géotechnique 2013, 63, 331-339. [CrossRef]

149. Khatami, H.R.; O'Kelly, B.C. Improving mechanical properties of sand using biopolymers. J. Geotech. Geoenviron. Eng. 2013, 139, 1402-1406. [CrossRef]

150. Chang, I.; Im, J.; Cho, G.-C. Geotechnical engineering behaviors of gellan gum biopolymer treated sand. Can. Geotech. J. 2016, 53, 1658-1670. [CrossRef]

151. Qureshi, M.U.; Chang, I.; Al-Sadarani, K. Strength and durability characteristics of biopolymer-treated desert sand. Geomech. Eng. 2017, 12, 785-801. [CrossRef] 
152. Nugent, R.A.; Zhang, G.; Gambrell, R.P. Effect of exopolymers on the liquid limit of clays and its engineering implications. Transp. Res. Rec. 2009, 2101, 34-43. [CrossRef]

153. Sarkar, A. Mould and Core Material for the Steel Foundry; Elsevier: Amsterdam, The Netherland, 1967.

154. Chang, I.; Cho, G.-C. Geotechnical behavior of a beta-1,3/1, 6-glucan biopolymer-treated residual soil. Geomech. Eng. 2014, 7, 633-647. [CrossRef]

155. Albayrak, Z.N.K.; Gencer, G. The Usability of Clay/Pumice Mixtures Modified with Biopolymer as an Impermeable Liner. KSCE J. Civ. Eng. 2021, 25, 28-36. [CrossRef]

156. Chang, I.; Cho, G.-C. Shear strength behavior and parameters of microbial gellan gum-treated soils: From sand to clay. Acta Geotech. 2019, 14, 361-375. [CrossRef]

157. Smitha, S.; Sachan, A. Use of agar biopolymer to improve the shear strength behavior of sabarmati sand. Int. J. Geotech. Eng. 2016, 10, 387-400. [CrossRef]

158. Stephen, A.M.; Phillips, G.O. Food Polysaccharides and Their Applications; CRC press: Boca Raton, FL, USA, 2016.

159. Lee, S.; Chang, I.; Chung, M.-K.; Kim, Y.; Kee, J. Geotechnical shear behavior of xanthan gum biopolymer treated sand from direct shear testing. Geomech. Eng. 2017, 12, 831-847. [CrossRef]

160. Gilbert, R.; Najjar, S.; Shields, M. Importance of residual strengths in factors of safety and reliability. In Geosynthetics Research and Development in Progress; ASCE: Reston, VA, USA, 2005; pp. 1-6.

161. Morgan, R. Soil Erosion and Conservation; Blackwell Publ: Oxford, UK, 2005.

162. Mehdizadeh, A.; Disfani, M.M.; Evans, R.; Arulrajah, A.; Ong, D.E.L. Mechanical consequences of suffusion on undrained behaviour of a gap-graded cohesionless soil-an experimental approach. Geotech. Test. J. 2017, 40, 1026-1042. [CrossRef]

163. Chang, I.; Im, J.; Cho, G.-C. An environmentally-friendly geotechnical approach for soil erosion reduction using microbial biopolymers. In Geo-Chicago 2016; ASCE: Reston, VA, USA, 2016; pp. 17-24.

164. Donayre, A.; Sanchez, L.; Kim, S.; Aguilar, R.; Nakamatsu, J. Eco-friendly Improvement of Water Erosion Resistance of Unstable Soils with Biodegradable Polymers. In Proceedings of the IOP Conference Series: Materials Science and Engineering, Kuala Lumpur, Malaysia, 13-14 August 2018; p. 012044.

165. Lee, S.; Kwon, Y.-M.; Cho, G.-C.; Chang, I. Investigation of Biopolymer Treatment Feasibility to Mitigate Surface Erosion Using a Hydraulic Flume Apparatus. In Proceedings of the Geo-Congress 2020, Minneapolis, MN, USA, 25-28 February 2020; pp. 46-52.

166. Alsanad, A. Novel Biopolymer Treatment for Wind Induced Soil Erosion; Arizona State University: Tempe, AZ, USA, 2011.

167. Ayeldeen, M.; Negm, A.; El Sawwaf, M.; Gädda, T. Laboratory study of using biopolymer to reduce wind erosion. Int. J. Geotech. Eng. 2018, 12, 228-240. [CrossRef]

168. Kavazanjian, E., Jr.; Iglesias, E.; Karatas, I. Biopolymer soil stabilization for wind erosion control. In Proceedings of the 17th International Conference on Soil Mechanics and Geotechnical Engineering, Alexandria, Egypt, 5-9 October 2009; pp. 881-884.

169. Rushing, J.F.; Harrison, A.; Tingle, J.S.; Mason, Q.; McCaffrey, T. Evaluation of dust palliatives for unpaved roads in arid climates. J. Perform. Constr. Facil. 2006, 20, 281-286. [CrossRef]

170. Chen, R.; Lee, I.; Zhang, L. Biopolymer stabilization of mine tailings for dust control. J. Geotech. Geoenviron. Eng. 2015, 141, 04014100. [CrossRef]

171. Morgan, R.P.C.; Nearing, M. Handbook of Erosion Modelling; John Wiley \& Sons: Hoboken, NJ, USA, 2016.

172. Wong, S.T.; Ong, D.E.L.; Robinson, R.G. Behaviour of MH silts with varying plasticity indices. Geotech. Res. 2017, 4, 118-135. [CrossRef]

173. Cai, G.; Zhang, T.; Liu, S.; Li, J.; Jie, D. Stabilization mechanism and effect evaluation of stabilized silt with lignin based on laboratory data. Mar. Georesour. Geotechnol. 2016, 34, 331-340. [CrossRef]

174. Ayeldeen, M.; Negm, A.; El-Sawwaf, M.; Kitazume, M. Enhancing mechanical behaviors of collapsible soil using two biopolymers. J. Rock Mech. Geotech. Eng. 2017, 9, 329-339. [CrossRef]

175. Qureshi, M.U.; Al-Hilly, A.; Al-Zeidi, O.; Al-Barrami, A.; Al-Jabri, A. Vane shear strength of bio-improved sand reinforced with natural fibre. In Proceedings of the E3S Web of Conferences, Dalian, China, 29-31 October 2019; p. 12004.

176. Shogren, R.; Doane, W.; Garlotta, D.; Lawton, J.; Willett, J. Biodegradation of starch/polylactic acid/poly (hydroxyester-ether) composite bars in soil. Polym. Degrad. Stab. 2003, 79, 405-411. [CrossRef]

177. Chang, I.; Im, J.; Lee, S.-W.; Cho, G.-C. Strength durability of gellan gum biopolymer-treated Korean sand with cyclic wetting and drying. Constr. Build. Mater. 2017, 143, 210-221. [CrossRef]

178. Qureshi, M.; Al-Qayoudhi, S.; Al-Kendi, S.; Al-Hamdani, A.; Al-Sadrani, K. The effects of slaking on the durability of bio-improved sand. Int. J. Sci. Eng. Res. 2015, 6, 486-490.

179. Kirk, T.K. Effects of microorganisms on lignin. Annu. Rev. Phytopathol. 1971, 9, 185-210. [CrossRef]

180. Teaca, C.A.; Roşu, D.; Mustaţă, F.; Rusu, T.; Roşu, L.; Roşca, I.; Varganici, C.-D. Natural Bio-Based Products for Wood Coating and Protection against Degradation: A Review. BioResources 2019, 14, 4873-4901. [CrossRef]

181. Arab, M.G.; Mousa, R.; Gabr, A.; Azam, A.; El-Badawy, S.; Hassan, A. Resilient Behavior of Sodium Alginate-Treated Cohesive Soils for Pavement Applications. J. Mater. Civ. Eng. 2019, 31, 04018361. [CrossRef]

182. Goren, S.; Alagha, O. Soil treatment with lignin sulphide chemical stabilizer: Environmental and structural assessment. J. Residuals Sci. Technol. 2008, 5, 189-194.

183. Liu, Y.; Chang, M.; Wang, Q.; Wang, Y.; Liu, J.; Cao, C.; Zheng, W.; Bao, Y.; Rocchi, I. Use of sulfur-free lignin as a novel soil additive: A multi-scale experimental investigation. Eng. Geol. 2020, 269, 105551. [CrossRef] 
184. Pérez, I.P.; Pasandín, A.M.R.; Pais, J.C.; Pereira, P.A.A. Use of lignin biopolymer from industrial waste as bitumen extender for asphalt mixtures. J. Clean. Prod. 2019, 220, 87-98. [CrossRef]

185. Gopalakrishnan, K.; Ceylan, H.; Kim, S. Renewable biomass-derived lignin in transportation infrastructure strengthening applications. Int. J. Sustain. Eng. 2013, 6, 316-325. [CrossRef]

186. Ni, J.; Hao, G.-L.; Chen, J.-Q.; Ma, L.; Geng, X.-Y. The Optimisation Analysis of Sand-Clay Mixtures Stabilised with Xanthan Gum Biopolymers. Sustainability 2021, 13, 3732. [CrossRef]

187. Bouazza, A.; Gates, W.P.; Ranjith, P.G. Hydraulic conductivity of biopolymer-treated silty sand. Géotechnique 2009, 59, 71-72. [CrossRef]

188. Wu, F.; Li, G.; Li, H.-N.; Jia, J.-Q. Strength and stress-strain characteristics of traditional adobe block and masonry. Mater. Struct. 2013, 46, 1449-1457. [CrossRef]

189. Silveira, D.; Varum, H.; Costa, A.; Martins, T.; Pereira, H.; Almeida, J. Mechanical properties of adobe bricks in ancient constructions. Constr. Build. Mater. 2012, 28, 36-44. [CrossRef]

190. Sorsa, A.; Senadheera, S.; Birru, Y. Engineering Characterization of Subgrade Soils of Jimma Town, Ethiopia, for Roadway Design. Geosciences 2020, 10, 94. [CrossRef]

191. Mamlouk, M.S.; Zaniewski, J.P. Materials for Civil and Construction Engineers; Pearson Prentice Hall: Upper Saddle River, NJ, USA, 2006.

192. Hatakeyama, H.; Hatakeyama, T. Interaction between water and hydrophilic polymers. Thermochim. Acta 1998, 308, 3-22. [CrossRef]

193. Maghchiche, A.; Haouam, A.; Immirzi, B. Use of polymers and biopolymers for water retaining and soil stabilization in arid and semiarid regions. J. Taibah Univ. Sci. 2010, 4, 9-16. [CrossRef]

194. Jeong, B.; Kim, S.W.; Bae, Y.H. Thermosensitive sol-gel reversible hydrogels. Adv. Drug Deliv. Rev. 2012, 64, 154-162. [CrossRef]

195. Dehghan, H.; Tabarsa, A.; Latifi, N.; Bagheri, Y. Use of xanthan and guar gums in soil strengthening. Clean Technol. Environ. Policy 2019, 21, 155-165. [CrossRef]

196. Galán-Marín, C.; Rivera-Gómez, C.; Petric, J. Clay-based composite stabilized with natural polymer and fibre. Constr. Build. Mater. 2010, 24, 1462-1468. [CrossRef]

197. Jameson, G. Guide to Pavement Technology Part 4D: Stabilised Materials; Austroads: Sydney, Australia, 2019 ; ISBN 1925854124.

198. Kimmerling, R. Geotechnical Engineering Circular No. 6 Shallow Foundations; Federal Highway Administration. Office of Bridge Technology: Washington, NJ, USA, 2002.

199. Epa, U. Solid Waste Disposal Facility Criteria; EPA: Washington, DC, USA, 1993.

200. Shankar, M.U.; Muthukumar, M. Comprehensive review of geosynthetic clay liner and compacted clay liner. In Proceedings of the IOP Conference Series: Materials Science and Engineering, Busan, Korea, 25-27 August 2017; p. 032026.

201. Chen, R.; Ding, X.; Ramey, D.; Lee, I.; Zhang, L. Experimental and numerical investigation into surface strength of mine tailings after biopolymer stabilization. Acta Geotech. 2016, 11, 1075-1085. [CrossRef]

202. Day, S.R.; Ryan, C.R. State of the art in bio-polymer drain construction. In Slurry Walls: Design, Construction, and Quality Control; ASTM International: West Conshohocken, PA, USA, 1992.

203. Aminpour, M.; O'Kelly, B.C. Applications of biopolymers in dam construction and operation activities. In Proceedings of the Proceedings of the 2nd International Dam World Conference, Lisbon, Portugal, 2015; pp. 937-946.

204. Cheng, L.; Shahin, M.A.; Chu, J. Soil bio-cementation using a new one-phase low-pH injection method. Acta Geotech. 2019, 14, 615-626. [CrossRef]

205. Leong, H.Y.; Ong, D.E.L.; Sanjayan, J.G.; Nazari, A.; Kueh, S.M. Effects of Significant Variables on Compressive Strength of Soil-Fly Ash Geopolymer: Variable Analytical Approach Based on Neural Networks and Genetic Programming. J. Mater. Civ. Eng. 2018, 30, 04018129. [CrossRef]

206. Leong, H.; Ong, D.E.L.; Sanjayan, J.; Nazari, A. A genetic programming predictive model for parametric study of factors affecting strength of geopolymers. RSC Adv. 2015, 5, 85630-85639. [CrossRef]

207. Castellane, T.C.L.; Persona, M.R.; Campanharo, J.C.; de Macedo Lemos, E.G. Production of exopolysaccharide from rhizobia with potential biotechnological and bioremediation applications. Int. J. Biol. Macromol. 2015, 74, 515-522. [CrossRef]

208. Omoregie, A.I.; Ong, D.E.L.; Nissom, P.M. Assessing ureolytic bacteria with calcifying abilities isolated from limestone caves for biocalcification. Lett. Appl. Microbiol. 2019, 68, 173-181. [CrossRef]

209. Ong, D.E.L.; Yang, D.; Phang, S. Comparisons of finite element modeling of a deep excavation using SAGE-CRISP and PLAXIS. In Proceedings of the International Conferenceon Deep Excavations, Singapore, 28-30 June 2006; pp. $28-30$.

210. Ong, D.E.L. Benchmarking of FEM Technique Involving Deep Excavation, Pile-soil Interaction and Embankment Construction. In Proceedings of the 12th International Conference of IACMAG, Goa, India, 1-6 October 2008.

211. Ong, D.E.L.; Leung, C.; Chow, Y. Piles subject to excavation-induced soil movement in clay. In Proceedings of the Proceedings of the 13th European Conference on Soil Mechanics and Geotechnical Engineering, Prague, Czech Republic, 25-28 August 2003; pp. 777-782.

212. Ong, D.E.L.; Leung, C.F.; Chow, Y.K. Behavior of pile groups subject to excavation-induced soil movement in very soft clay. J. Geotech. Geoenviron. Eng. 2015, 135, 1462-1474. [CrossRef]

213. Ong, D.E.L.; Leung, C.; Chow, Y. Pile behavior due to excavation-induced soil movement in clay. I: Stable wall. J. Geotech. Geoenviron. Eng. 2006, 132, 36-44. [CrossRef] 
214. Cheng, W.-C.; Li, G.; Ong, D.E.L.; Chen, S.-L.; Ni, J.C. Modelling liner forces response to very close-proximity tunnelling in soft alluvial deposits. Tunn. Undergr. Space Technol. 2020, 103, 103455. [CrossRef]

215. Mehdizadeh, A.; Disfani, M.M.; Evans, R.; Arulrajah, A.; Ong, D.E.L. Discussion of “development of an internal camera-based volume determination system for triaxial testing" by se Salazar, a. Barnes and Ra Coffman. The technical note was published in geotechnical testing journal, vol. 38, no. 4, 2015. Geotech. Test. J. 2016, 39, 165-168. [CrossRef] 